\title{
Computational Chemistry-based identification of Ultra-Low Temperature Water-Gas-Shift Catalysts
}

\author{
Final Technical Report \\ September 1, 2006 - June 30, 2008
}

Professor Manos Mavrikakis

June 2008

DOE Award Number: DE-FG26-06NT42740

Department of Chemical and Biological Engineering

University of Wisconsin - Madison

Madison, WI 53706 


\section{Disclaimer}

This report was prepared as an account of work sponsored by an agency of the United States Government. Neither the United States Government nor any agency thereof, nor any of their employees, makes any warranty, express or implied, or assumes any legal liability or responsibility for the accuracy, completeness, or usefulness of any information, apparatus, product, or process disclosed, or represents that its use would not infringe privately owned rights. Reference herein to any specific commercial product, process, or service by trade name, trademark, manufacturer, or otherwise does not necessarily constitute or imply its endorsement, recommendation, or favoring by the United States Government or any agency thereof. The views and opinions of authors expressed herein do not necessarily state or reflect those of the United States Government or any agency thereof. 


\begin{abstract}
$\underline{\text { Abstract }}$
The current work seeks to identify novel, catalytically-active, stable, poisonresistant LWGS catalysts that retain the superior activity typical of conventional $\mathrm{Cu}$ catalysts but can be operated at similar or lower temperatures. A database for the Binding Energies (BEs) of the LWGS relevant species, namely $\mathrm{CO}, \mathrm{O}$ and $\mathrm{OH}$ on the most-stable, close-packed facets of a set of 17 catalytically relevant transition metals was established. This BE data and a database of previously established segregation energies was utilized to predict the stability of bimetallic NSAs that could be synthesized by combinations of the 17 parent transition metals. NSAs that were potentially stable both in vacuo and under the influence of strong-binding WGS intermediates were then selected for adsorption studies. A set of 40 NSAs were identified that satisfied all three screener criteria and the binding energies of $\mathrm{CO}, \mathrm{O}$ and $\mathrm{OH}$ were calculated on a set of 66,43 and 79 NSA candidates respectively. Several NSAs were found that bound intermediates weaker than the monometallic catalysts and were thus potentially poison-resistant. Finally, kinetic studies were performed and resulted in the discovery of a specific NSA-based bimetallic catalyst $\mathrm{Cu} / \mathrm{Pt}$ that is potentially a promising LWGS catalyst. This stable $\mathrm{Cu} / \mathrm{Pt}$ subsurface alloy is expected to provide facile $\mathrm{H}_{2} \mathrm{O}$ activation and remain relatively resistant from the poisoning by $\mathrm{CO}, \mathrm{S}$ and formate intermediates.
\end{abstract}




\section{Table of Contents}

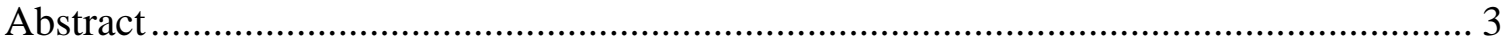

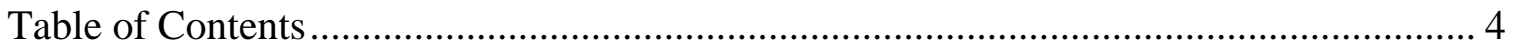

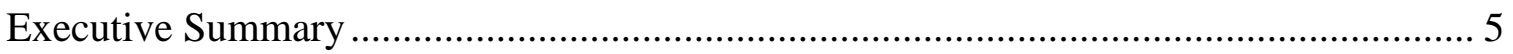

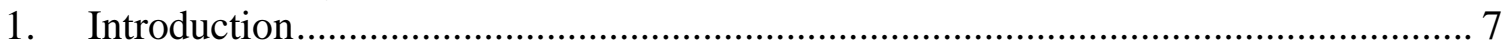

1.1. Motivation and Background ........................................................................... 7

1.2. Overview of our Calculation Approach .......................................................... 7

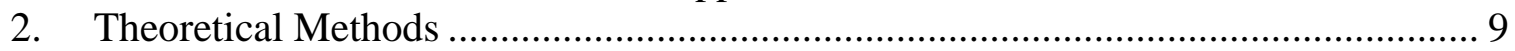

3. Results and Discussion ...................................................................................... 9

3.1. Adsorption of $\mathrm{CO}, \mathrm{O}$ and $\mathrm{OH}$ on monometallic facets....................................... 9

3.2. Screening of potential NSA catalysts in the presence of WGS relevant adsorbates..................................................................................................... 11

3.3. Adsorption of $\mathrm{CO}, \mathrm{O}$ and $\mathrm{OH}$ on NSAs (sub-surface alloys and overlayers)... 14

3.4. Kinetic Studies for WGS on selected NSAs ...................................................... 17

4. Conclusions / Summary of accomplishments ………………………………........... 19

5. Plans for future work .......................................................................................... 19

6. Graphical Material List / Table of Figures ……………………………………..... 20

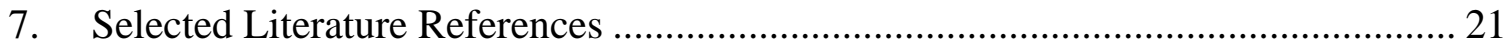

8. List of Published Journal Articles......................................................................... 21

9. Awards/Distinctions for the PI............................................................................ 21

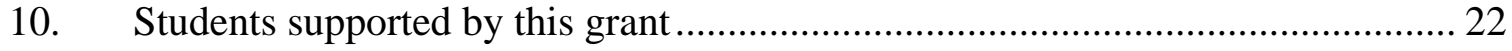

11. List of Acronyms and Abbreviations................................................................. 22 


\section{Executive Summary}

The Low Temperature Water Gas Shift (LWGS) Reaction $\left(\mathrm{CO}+\mathrm{H}_{2} \mathrm{O} \rightarrow \mathrm{CO}_{2}+\mathrm{H}_{2}\right)$ is an industrially important reaction because of its key role in the production and purification of $\mathrm{H}_{2}$ for various applications. In addition to its application for $\mathrm{H}_{2}$ production and purification from fossil-fuels, LWGS is also employed in fuel cells to remove any residual CO impurity which has potential to severely interfere with fuel cell operation. The exothermic nature of the WGS reaction necessitates operation at relatively low temperatures in order to obtain a favorable equilibrium distribution that maximizes the desired products $\left(\mathrm{CO}_{2}+\mathrm{H}_{2}\right)$. The low-temperature operation, unfortunately, causes a concomitant penalty on the reaction rates that might be achieved by conventional catalysts. $\mathrm{Cu}$ is the typical catalyst employed for most industrial applications of LWGS, yet there exists considerable incentive for the discovery of novel, poison-resistant, LWGS catalysts that demonstrate long-term stability, and provide activity improvement over $\mathrm{Cu}$ and yet are able to operate at similar or lower temperatures. In spite of its long history as a LWGS catalyst the fundamental reaction mechanisms for LWGS on $\mathrm{Cu}$ and other transition metals are still the subject of considerable debate and hence our first-principles based calculations can help in providing the insights required for truly rational LWGS catalyst design.

Our first-principles studies tried to identify stable, poison-resistant, bimetallic Near Surface Alloys (NSAs) that would be potentially suitable LWGS Catalysts. We restricted our studies to alloys made from a set of 17 catalytically relevant Transition Metals. Although bimetallic alloys can exist in a variety of configurations NSAs were the only class studied in this project. NSAs are alloys with a solute metal near the surface of a host metal at concentrations different from those in the bulk. Numerous recent studies have attributed NSAs with novel electronic and catalytic properties (for hydrogen storage applications and fuel cell electrodes) considerably distinct from the parent metals that they are constituted from. In addition NSAs can be synthesized at compositions that would not be deemed to be thermodynamically stable for conventional bulk alloys. Previous work on $\mathrm{Cu}$ had identified the ease of $\mathrm{H}_{2} \mathrm{O}$ activation along with the strength of $\mathrm{OH}, \mathrm{CO}$ and $\mathrm{O}$ binding as reasonable descriptors of WGS activity and hence our studies started with calculations for the adsorption of these adsorbates on the set of 17 transition metals. All high-symmetry sites on the close packed facets of each transition metal were considered and the binding energies (BEs) and site-preferences were evaluated. Calculations for Sulfur adsorption were also undertaken in view of the fact that Sulfur is one of the most relevant poisons that negatively affects the activity of WGS catalysts.

We found that the noble metals tend to bind the adsorbates weaker than the rest and for the adsorption of $\mathrm{CO}$ in particular there is a distinct "BE-gap" between the binding strength of adsorbates on the noble metals and the others. $\mathrm{Cu}$, the conventional LWGS catalyst exhibits a very low $\mathrm{BE}_{\mathrm{CO}}$. After having established this database for the $\mathrm{BE}$ of adsorbates on noble metals we proceeded to calculations on bimetallic NSAs. The primary criterion we applied was the long-term stability of these NSAs in vacuo and in presence of adsorbates likely to be in the ambient of LWGS processing. A set of 
"screener-plots" were constructed by utilizing the BE data for adsorbates on the monometallic systems and a previous database of segregation energies. In the interest of computational feasibility this set was further pruned by applying heuristics based on past experience and the BEs for $\mathrm{CO}, \mathrm{O}$ and $\mathrm{OH}$ were established on a 66, 43 and 79 NSA candidates respectively. 40 NSAs were found that satisfied the criteria of surviving all three screeners. Both overlayer and sub-surface alloy type NSAs were considered and a database of $\mathrm{CO}, \mathrm{O}$ and $\mathrm{OH}$ BEs was established. This database serves as a fertile source to apply data-mining approaches for rational catalyst design as a part of this and future studies. Several NSAs were discovered that bind adsorbates weaker than any of the monometallic systems studied so far e.g. $\mathrm{Au}^{*} / \mathrm{Ir}$, and $\mathrm{Pt}^{*} / \mathrm{Cu}$ for $\mathrm{O}$ and $\mathrm{Pt} * / \mathrm{Cu}$ for $\mathrm{OH}$. In addition some NSAs display an interesting behavior since they bind adsorbates with a strength that is weaker than what we would expect on the basis of either parent-metal e.g. $\mathrm{Au}^{*} / \mathrm{Re}$ binds $\mathrm{O}$ weaker than both $\mathrm{Au}$ and $\mathrm{Re}$. We discovered that the metal exposed on the surface of the NSA catalyst has the primary dominant influence on adsorbate BE in most cases whereas the underlying metal only has a weaker modulating influence. Further, we identified four NSAs that bind $\mathrm{CO}$ weaker than $\mathrm{Cu}$ and hence might prevent CO-poisoning of the LWGS catalyst.

In the last stage of the project we performed Minimum Energy Pathway (MEP) calculations using the climbing-image Nudged Elastic Band (NEB) method to evaluate the thermochemistry and kinetics for $\mathrm{H}_{2} \mathrm{O}$ activation on a set of carefully selected promising WGS catalysts. Specifically, the elementary step $\mathrm{H}_{2} \mathrm{O} \rightarrow \mathrm{OH}+\mathrm{H}$ was analyzed since previous work has implicated this as a Rate Determining Step (RDS) on a variety of TMs including $\mathrm{Cu}$. The most significant bimetallic alloy catalyst discovered was the $\mathrm{Cu} / \mathrm{Pt}$ system which provides facile $\mathrm{H}_{2} \mathrm{O}$ activation yet binds the products $(\mathrm{OH}+$ $\mathrm{H})$ weaker than $\mathrm{Cu}$. This catalyst was shown to be significantly resistant to poisoning by both $\mathrm{CO}$ and formate species by virtue of their weak adsorption. This Cu/Pt NSA shows an enhancement of $\mathrm{Cu}$ concentration in the first sub-surface of the Pt host and this system was demonstrated to be stable in CO-rich environments and thus resistant to CO-induced segregation and reconstruction. Finally, verification of the superior nature of the $\mathrm{Cu} / \mathrm{Pt}$ catalyst was performed by XPS, TPD and STM techniques undertaken by our collaborating-researchers. Thus the major success of the project was the establishment of databases for the BEs of $\mathrm{CO}, \mathrm{O}$ and $\mathrm{OH}$ on transition-metals and NSAs and further in utilizing this database (in conjunction with stability criteria) for the discovery of a novelLWGS catalytic system, $\mathrm{Cu} / \mathrm{Pt}$. 


\section{Introduction}

\subsection{Motivation and Background}

The Low Temperature Water Gas Shift (LWGS) Reaction $\left(\mathrm{CO}+\mathrm{H}_{2} \mathrm{O} \rightarrow \mathrm{CO}_{2}+\mathrm{H}_{2}\right)$ is an industrially important reaction because of its key role in the production and purification of $\mathrm{H}_{2}$ for various applications. Several dominant routes for $\mathrm{H}_{2}$ production from fossil fuels incorporate the WGS reaction at some stage in their processing scheme, most commonly as a sequence at high temperature and low temperature conditions. Another important LWGS application is the purification of feed $\mathrm{H}_{2}$ for low temperature fuel cells by removal of residual CO since most fuel cells mandate stringent limits on the CO concentrations they can tolerate. The WGS reaction is somewhat exothermic ( $\Delta H_{298}^{0} \sim-40 \mathrm{~kJ} / \mathrm{mol}$ ) and hence must be operated at relatively low temperatures in order to drive the reaction equilibrium in favor of the desired products $\left(\mathrm{CO}_{2}+\mathrm{H}_{2}\right)$. In turn, low temperature places penalties on the reaction rates and that is why most large-scale industrial operations employ a high temperature WGS reactor followed by a LWGS reactor. For other applications with a space constraint, most notably automotive fuelcells, such a two-stage scheme is not viable. $\mathrm{Cu}$ is currently the catalyst of choice for most LWGS applications and at the relatively low temperatures involved $\left(<250^{\circ} \mathrm{C}\right)$ the native activity of $\mathrm{Cu}$ catalysts is low and imposes significant kinetic limitations on the process. Despite a number of experimental studies $^{1-3}$, the detailed LWGS reaction mechanism on various transition metals remains elusive, precluding truly rational catalyst improvements. As a result, significant incentives prevail for the identification of novel LWGS catalysts that provide activity improvements over $\mathrm{Cu}$ and yet are able to operate at similar or, even better, lower temperatures.

\subsection{Overview of our Calculation Approach}

The principal goal of our project is the identification of stable, bimetallic, Near Surface Alloy (NSA) based LWGS catalysts that satisfy the aforementioned dual 
objectives of high-activity and low temperature operation. We employ a sate-of-the-art, first-principles approach based on periodic, self-consistent Density Functional Theory (DFT) to screen and select a set of potentially promising LWGS catalysts and subsequently obtain a detailed understanding of the LWGS reaction mechanism on these selected bimetallic alloys by means of detailed kinetic studies. Our study considers bimetallic formulations derived from a set of 17 catalytically relevant transition metals ( $\mathrm{Au}, \mathrm{Ag}, \mathrm{Cu}, \mathrm{Pd}, \mathrm{Pt}, \mathrm{Ir}, \mathrm{Ni}, \mathrm{Co}, \mathrm{Rh}, \mathrm{Fe}, \mathrm{Os}, \mathrm{Ru}, \mathrm{Re}, \mathrm{Mo}, \mathrm{W}$, Ta and V). A catalytically active nanoparticle would consist of several different crystal facets of these metals but the low-index, close-packed facets could be expected to dominate. Hence we focus on these, stable, low-energy facets of the transition metals and Near Surface Alloys under study.

Our study can be divided into several stages. Foremost we start with calculations for evaluating the binding energy $(\mathrm{BE})$ for the intermediates of interest $(\mathrm{O}, \mathrm{OH}$ and $\mathrm{CO}$ ) on the close-packed facets of the 17 pure transition metals. The next stage involves the study of the stability of these alloys in- vacuo and also in the presence of the relevant adsorbed intermediates. The BEs on pure metals and knowledge of the segregation energies of the transition metals allows us to construct "screener plots" for each of these adsorbates. Based on these plots we identify bimetallic combinations that might be stable yet active. This then leads to the next stage wherein we perform calculations to evaluate the BEs for these adsorbates on a set of promising NSAs. Finally we focus on a small number of NSAs and perform kinetic calculations on these for $\mathrm{H}_{2} \mathrm{O}$ activation, typically the most difficult step in WGS. Finally, Sulfur is a common poison for these catalysts and hence the binding of Sulfur was also studied on several of these alloys to probe their resistance to Sulfur poisoning. In the following sections we try to summarize the results of these calculations. 


\section{Theoretical Methods}

All calculations are performed using the total energy code DACAPO ${ }^{4,5}$. Adsorption is allowed on only one of the two surfaces of the slab and the electrostatic potential is adjusted accordingly. Calculations are performed spin-polarized where necessary (e.g.: metals or alloys including: $\mathrm{Fe}, \mathrm{Co}$, or $\mathrm{Ni}$ ). We use a 2x2x4 unit cell with 5 equivalent layers of vacuum in between successive slabs and relax the top two layers of the slabs. The Kohn-Sham one-electron valence states are expanded in a basis of plane waves with a kinetic energy below $25 \mathrm{Ry}$. The exchange-correlation energy and potential are described by the generalized gradient approximation (GGA-PW91); the ionic cores are described by ultrasoft pseudopotentials. The surface Brillouin zone is sampled with a $4 \times 4 \times 1$ Monkhorst-Pack or a Chadi-Cohen k point set, as appropriate.

\section{Results and Discussion}

\subsection{Adsorption of $\mathrm{CO}, \mathrm{O}$ and $\mathrm{OH}$ on monometallic facets}

In the first part of the project we performed calculations for the adsorption of $\mathrm{CO}$, $\mathrm{O}$ and $\mathrm{OH}$ on the closed packed facets of all 17 transition metals under investigation. The spectrum plot (Figure 1) shows the magnitude of $\mathrm{BE}$ 's for $\mathrm{CO}$. We found that $\mathrm{BE}_{\mathrm{CO}}$ spans a range of about $2.4 \mathrm{eV}$ with $\mathrm{Ag}$ binding the weakest (-0.3 eV) and $\mathrm{V}$ the strongest (-2.69 $\mathrm{eV})$. The noble metals $\mathrm{Ag}, \mathrm{Au}$ and $\mathrm{Cu}$ form a group of weak binding metals and every other metal binds $\mathrm{CO}$ stronger than these; in fact these three metals have a substantially superior performance than the rest and a $\mathrm{BE}_{\mathrm{CO}}$ "gap" of about $1 \mathrm{eV}$ separates this group from the other metals. Previous DFT studies in our group had identified the strength of CO binding as one of the two main descriptors characterizing WGS activity (the other being the ease of $\mathrm{H}_{2} \mathrm{O}$ activation). Cu performs well for LWGS due to a combination of a medium strength of $\mathrm{CO}$ binding and a rather facile $\mathrm{H}_{2} \mathrm{O}$ activation; our goal was to find NSAs that could bridge (or even better, transcend) the gap around $\mathrm{Cu}$ on this spectrum plot, while retaining the ability to perform facile $\mathrm{H}_{2} \mathrm{O}$ activation. 


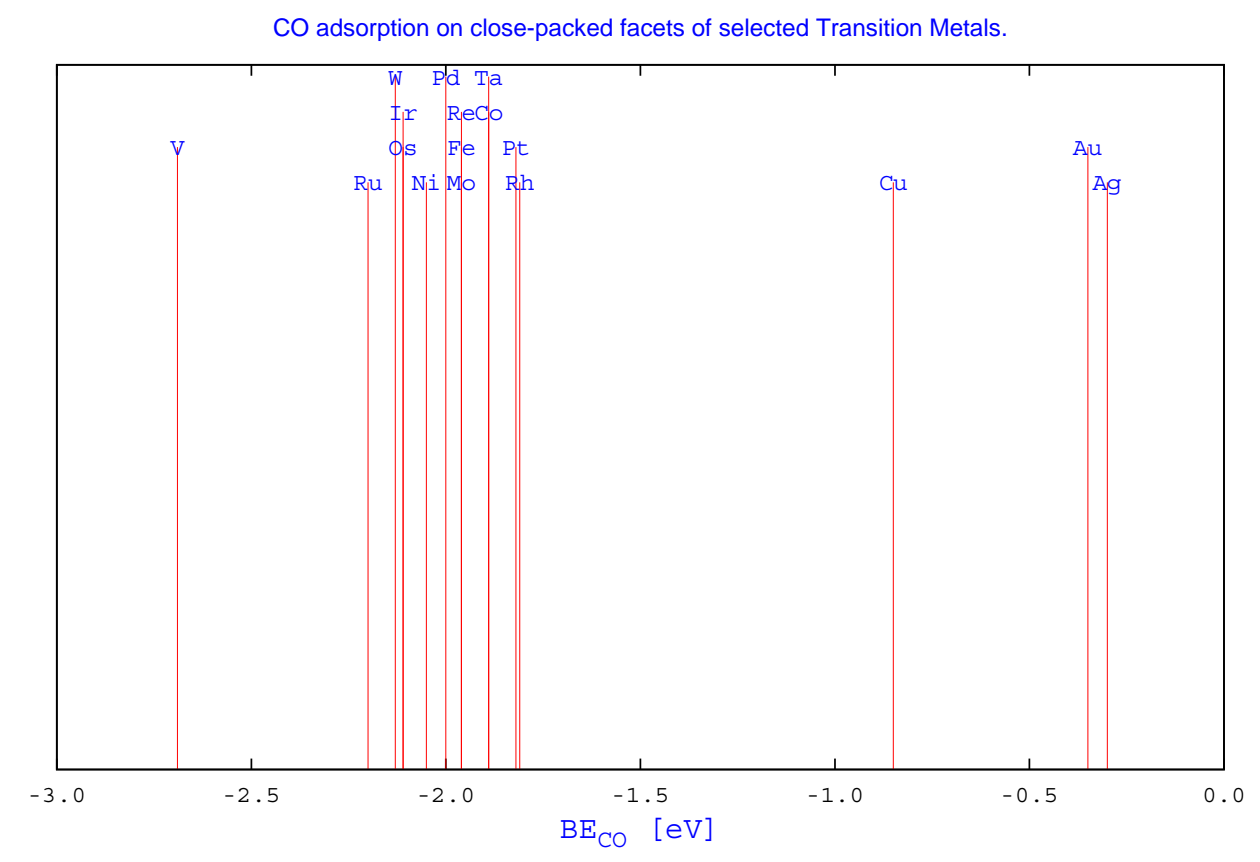

Figure 1 Strength of $\mathrm{CO}$ binding on monometallic transition-metal surfaces.

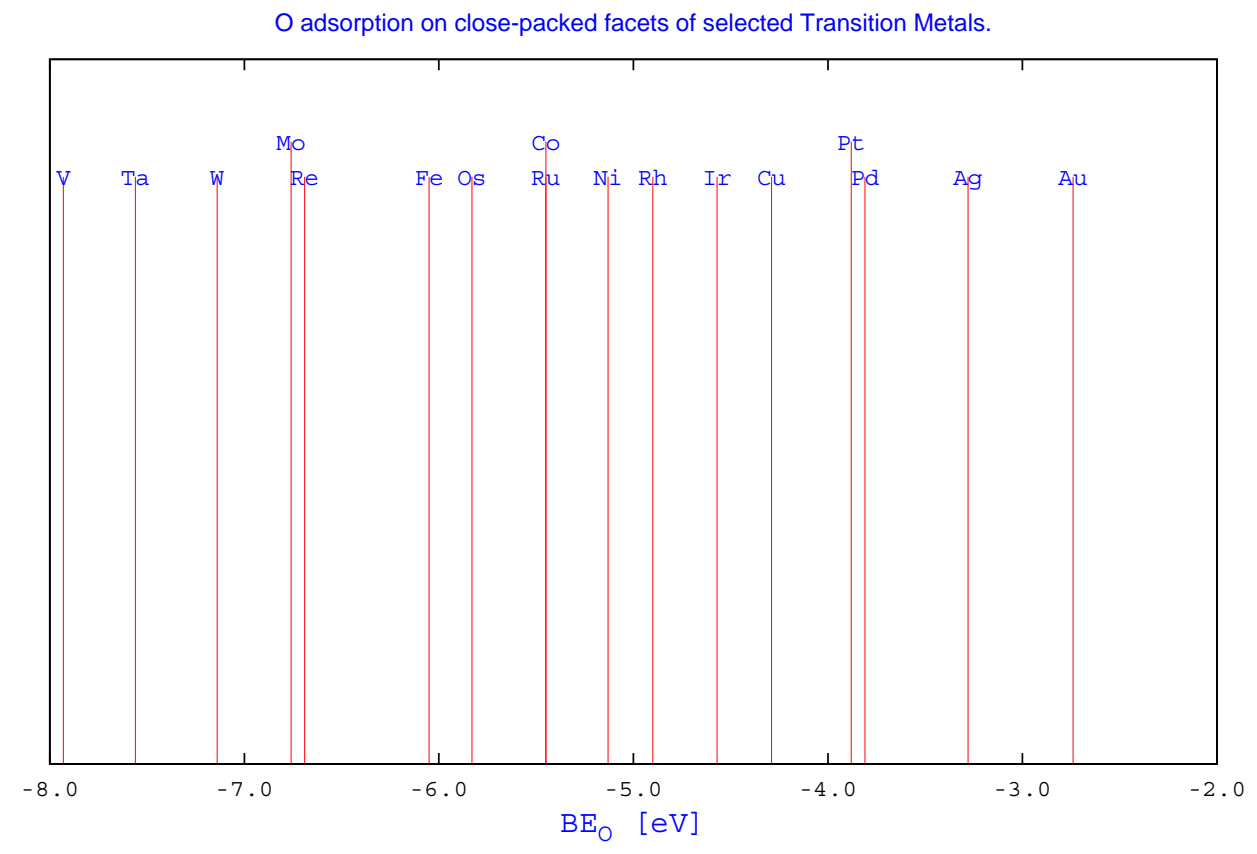

Figure 2 Strength of $\mathbf{O}$ binding on monometallic transition-metal surfaces. 


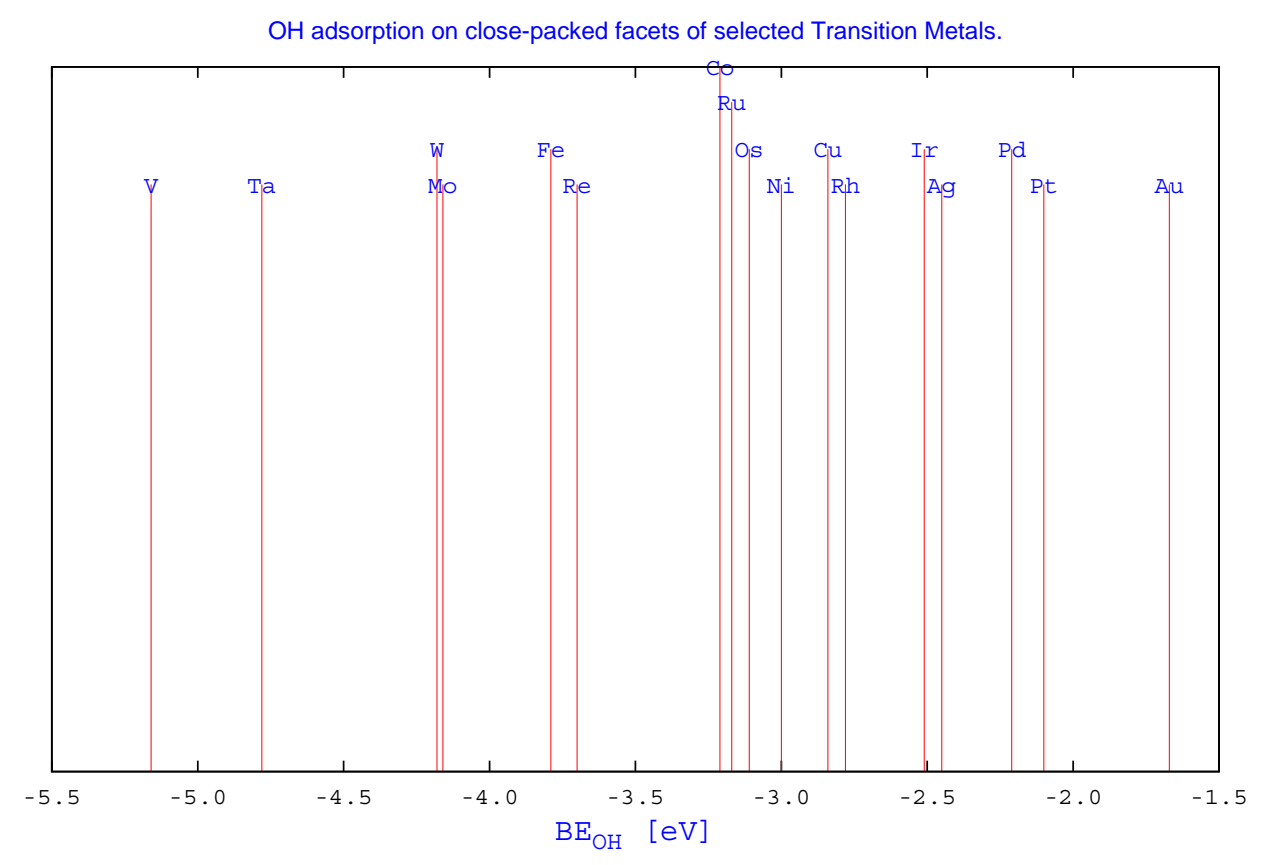

Figure 3 Strength of hydroxyl (-OH) binding on monometallic transition-metal surfaces.

Having obtained the CO BE's we moved on to analyze the trends for other species of relevance i.e. $\mathrm{O}$ and $\mathrm{OH}$. Similar calculations were performed and the results are summarized in Figure 2 and Figure 3, respectively. For Oxygen, the BE's span a range of about $5.2 \mathrm{eV}$ with Au binding the weakest $(-2.74 \mathrm{eV})$ and $\mathrm{V}$ the strongest $(-7.93 \mathrm{eV})$. The $\mathrm{OH}$ spectrum plot (Figure 3) indicates that a range of about $3.5 \mathrm{eV}$ is spanned and again, Au binds the weakest $(-1.67 \mathrm{eV})$ and $\mathrm{V}$ the strongest $(-5.16 \mathrm{eV})$. In all cases, Vanadium binds the adsorbates strongest whereas the noble metals are weak binders. The CO spectrum (Figure 1) is distinctive in two respects; the very weak binding exhibited by $\mathrm{Cu}$ and the presence of a "BE gap".

\subsection{Screening of potential NSA catalysts in the presence of WGS relevant adsorbates}

Having obtained the BE's for $\mathrm{CO}, \mathrm{O}$ and $\mathrm{OH}$ on this set of 17 Transition Metal surfaces we then proceeded to identify and characterize potential NSAs from the viewpoint of their LWGS activity. Before we delve into the details of our calculations a 
short introduction to NSAs in general and our notation and setup in particular is warranted. NSAs are alloys wherein a solute metal is present near the surface of a host metal in concentrations different from those of the bulk. As opposed to stable bulk binary alloys, for the existence of which, bulk miscibility is an essential precondition, it is possible to sustain NSAs in a stable configuration at concentrations deemed immiscible in a conventional bulk phase diagram. We focused on NSAs as promising LWGS catalysts in light of their novel electronic properties and superior catalytic behavior demonstrated by previous DFT studies in our group (pertaining to hydrogen storage, and fuel cell electrodes) and also theoretical and experimental investigations by other researchers ${ }^{6-8}$. Two idealized classes of NSAs are the overlayer and sandwich structures. The former is defined as a structure where the host is totally covered by a monolayer of a solute whereas the latter has a single layer of solute embedded in the next-to-surface layer of a host. In the notation that we adopt $X * / Y$ denotes an overlayer structure with the species $\mathrm{X}$ (solute) in the outermost layer and the species $\mathrm{Y}$ (host) present in the bulk of the slab. On the other hand, the notation $\mathrm{Y} / \mathrm{X}$ denotes a sandwich structure with solute $\mathrm{Y}$ embedded in bulk X. These features of NSA morphology are graphically illustrated in Figure 4.

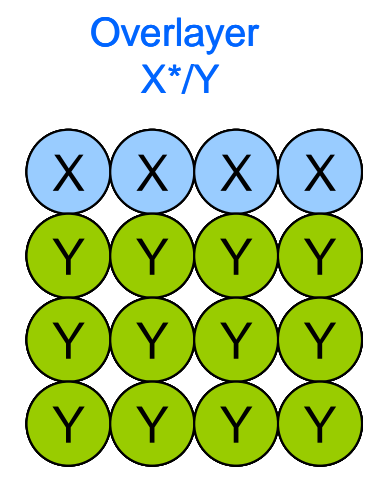

(a)

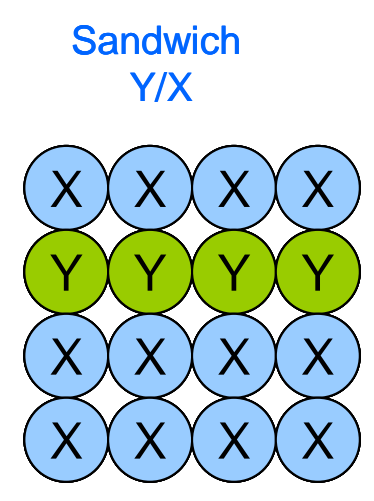

(b)

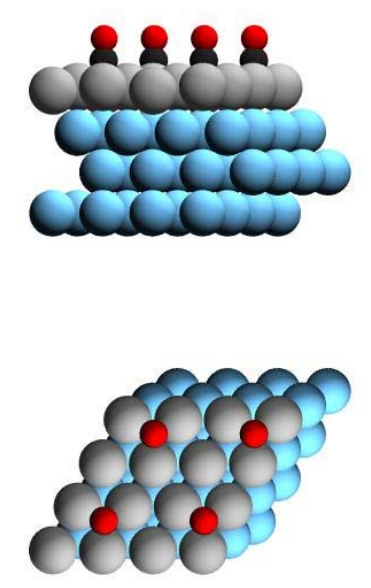

(c)

\section{Figure 4 Schematic overview of NSA structure and notation.}

(a) $\mathrm{X} / \mathrm{Y}$ Overlayer structure. $\mathrm{X}=$ Impurity; $\mathrm{Y}=$ Host. (b) $\mathrm{Y} / \mathrm{X}$ Sandwich (or subsurface alloy) structure. $Y=I m p u r i t y ; X=H o s t$. (c) Cross-section and top views of a 4 layer $\mathrm{Pt} * / \mathrm{Ru}$ overlayer NSA with CO adsorbed at the fcc site. 
Recall that our desire was to calculate the BE's of $\mathrm{CO}, \mathrm{O}$ and $\mathrm{OH}$ on a set of NSA structures that survived the test of surface stability in the presence of these adsorbates and then based on the strength of the BE's on these candidate NSAs identify potentially promising NSA catalysts for a detailed kinetic study of $\mathrm{H}_{2} \mathrm{O}$ activation. The stability can be estimated by using the segregation energy database for Transition Metals established by Ruban et al. ${ }^{9}$ and then following the two step procedure developed by Greeley and Mavrikakis. $^{10}$. First, the stability of the NSA is examined without reference to an adsorbate and then in a subsequent step the influence of adsorbate-induced segregation is accounted for. Thus, there are two competing factors: the segregation energy and the BE difference of the metal pair under consideration and the individual magnitudes and signs determine whether the NSA would retain its stable under vacuum configuration. The details of these screening calculations for the CO species are shown in Figure 5 which ultimately identifies a set of "survivors" when the screening criteria mentioned earlier are applied. Some representative NSAs are labeled in Figure 5, but in general any point that does not fall in the hatched region was a suitable candidate for further study. Similar plots were developed to investigate the effects of $\mathrm{O}$ and $\mathrm{OH}$ induced segregation separately but are not included in this report for the sake of brevity.

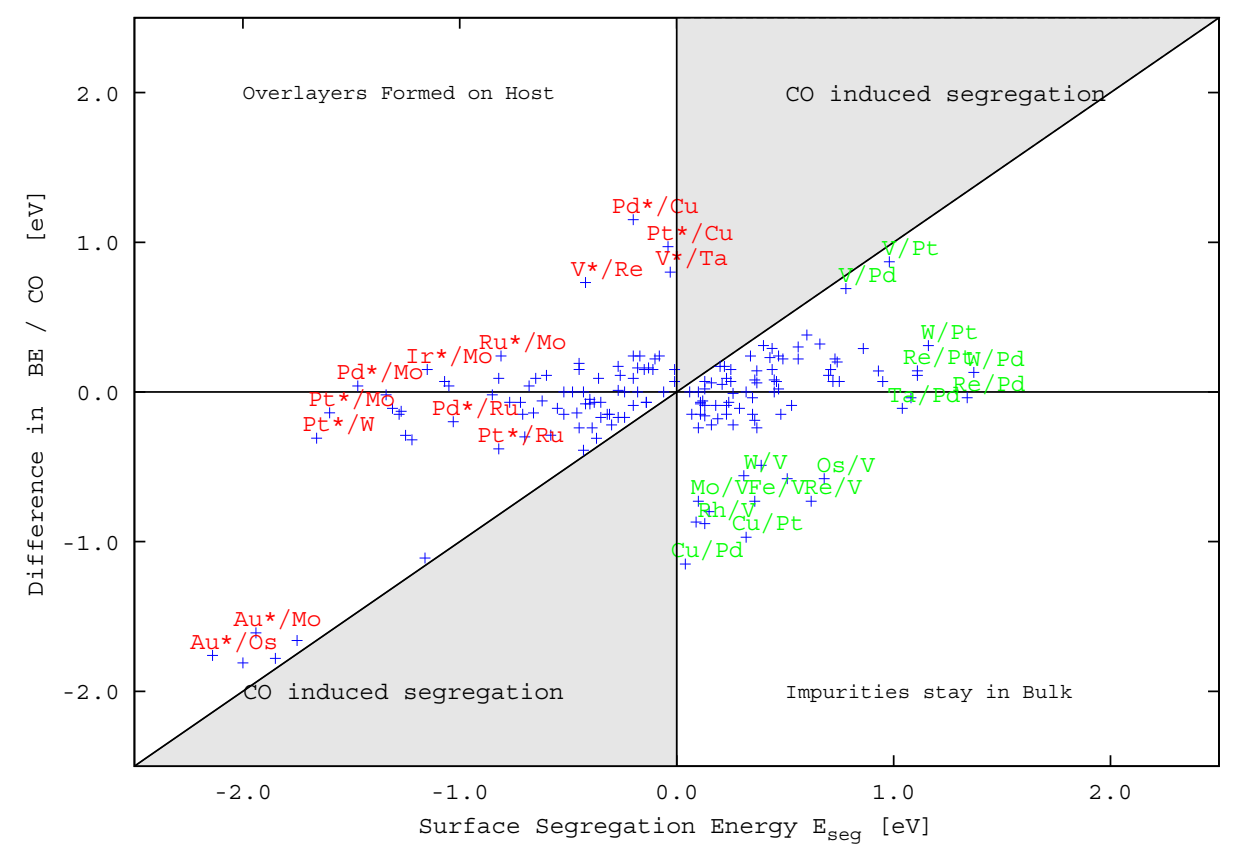


Figure 5: The "CO screener plot": Identification of NSAs stable in a CO rich environment:

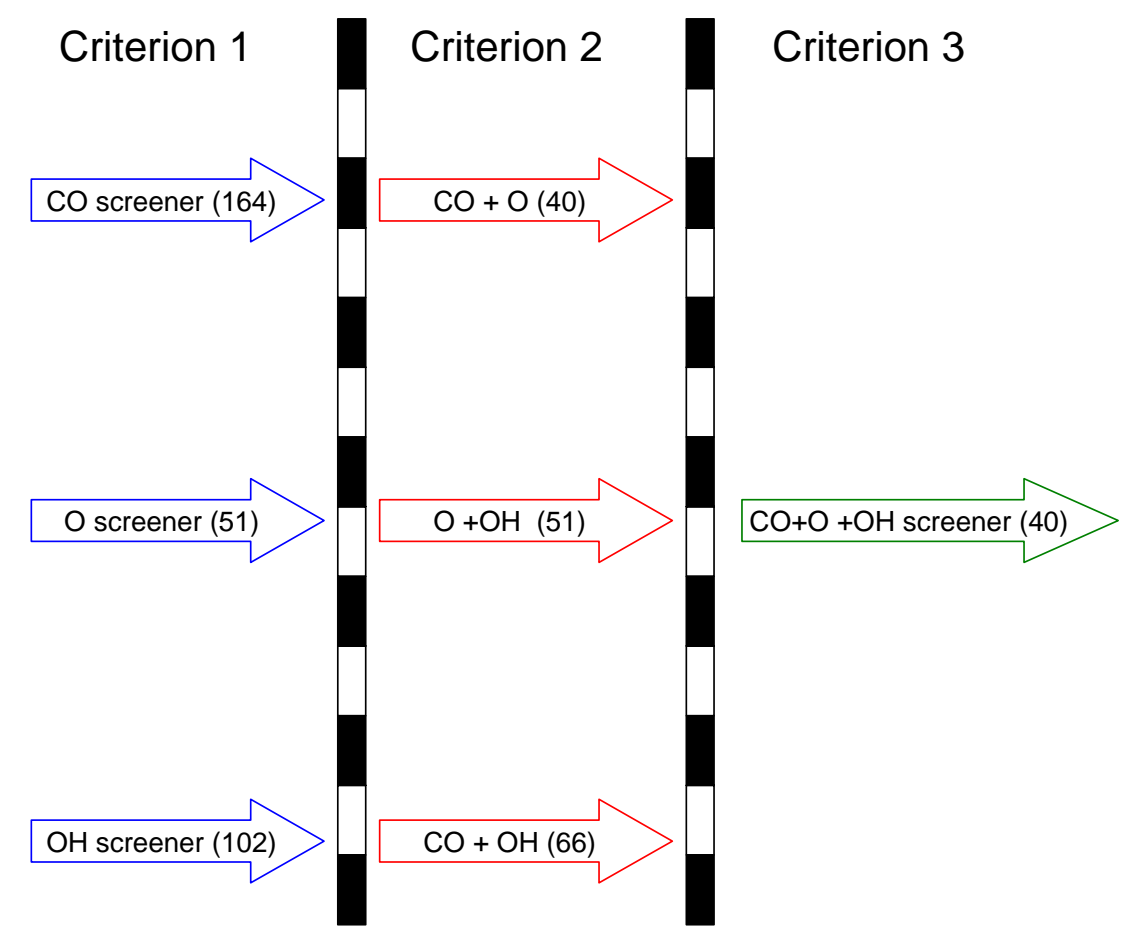

Figure 6 Employment of a cascade of screening criteria for the reduction of the set of potentially stable LWGS catalysts.

\subsection{Adsorption of $\mathrm{CO}, \mathrm{O}$ and $\mathrm{OH}$ on NSAs (sub-surface alloys and overlayers)}

It was not computationally feasible to evaluate $\mathrm{CO}, \mathrm{O}$ and $\mathrm{OH} \mathrm{BE}$ 's on all the “survivor” NSA systems. We applied heuristics based on our past experience to select the most promising NSAs. 66 NSAs were analyzed for $\mathrm{BE}_{\mathrm{CO}}, 43$ NSAs for $\mathrm{BE}_{\mathrm{O}}$ and 79 NSAs for $\mathrm{BE}_{\mathrm{OH}}$. All high symmetry sites were tested to establish the best binding sites on these facets. This set of calculations, although laborious, allows us to construct a comprehensive database of Binding Energies for $\mathrm{CO}, \mathrm{O}$ and $\mathrm{OH}$ which is a fertile source to apply data-mining approaches for rational catalyst design. It would be cumbersome to represent the entire dataset in a plot, but Figure 7, Figure 8 and Figure 9 give an overview by plotting a sampling of the NSA systems considered. It is evident that for all the 
adsorbates studied the NSAs succeed in bridging the gaps in the BE Spectra of the monometallic systems in a quasi-continuous way. At the same time, we discover some NSAs (for example: $\mathrm{Au}^{*} / \mathrm{Ir}, \mathrm{Pt}^{*} / \mathrm{Cu}$ for $\mathrm{O}$; $\mathrm{Pt}^{*} / \mathrm{Cu}$ for $\mathrm{OH}$ ) that bind adsorbates weaker than any of the monometallic catalysts studied so far. This special behavior in which NSAs exhibit properties beyond the range expected on the basis of either of their constituent components is particularly noteworthy. Several NSAs bind with strength weaker than what would be expected on the basis of the binding characteristics of the constituent parent metals (e.g. Au*/Re binds $\mathrm{O}$ weaker than both $\mathrm{Au}$ and $\mathrm{Re}$ ). Although not obvious from the Figures presented here, deeper analysis reveals that in most cases the metal exposed on the surface of the NSA exerts the primary, dominant influence on the BE while the underlying metal serves to modulate this binding strength. We identify 4 NSAs that bind $\mathrm{CO}$ weaker than $\mathrm{Cu}$, the reference LWGS catalyst, and hence would allow a considerable reduction in the potential for $\mathrm{CO}$ poisoning of the catalyst.

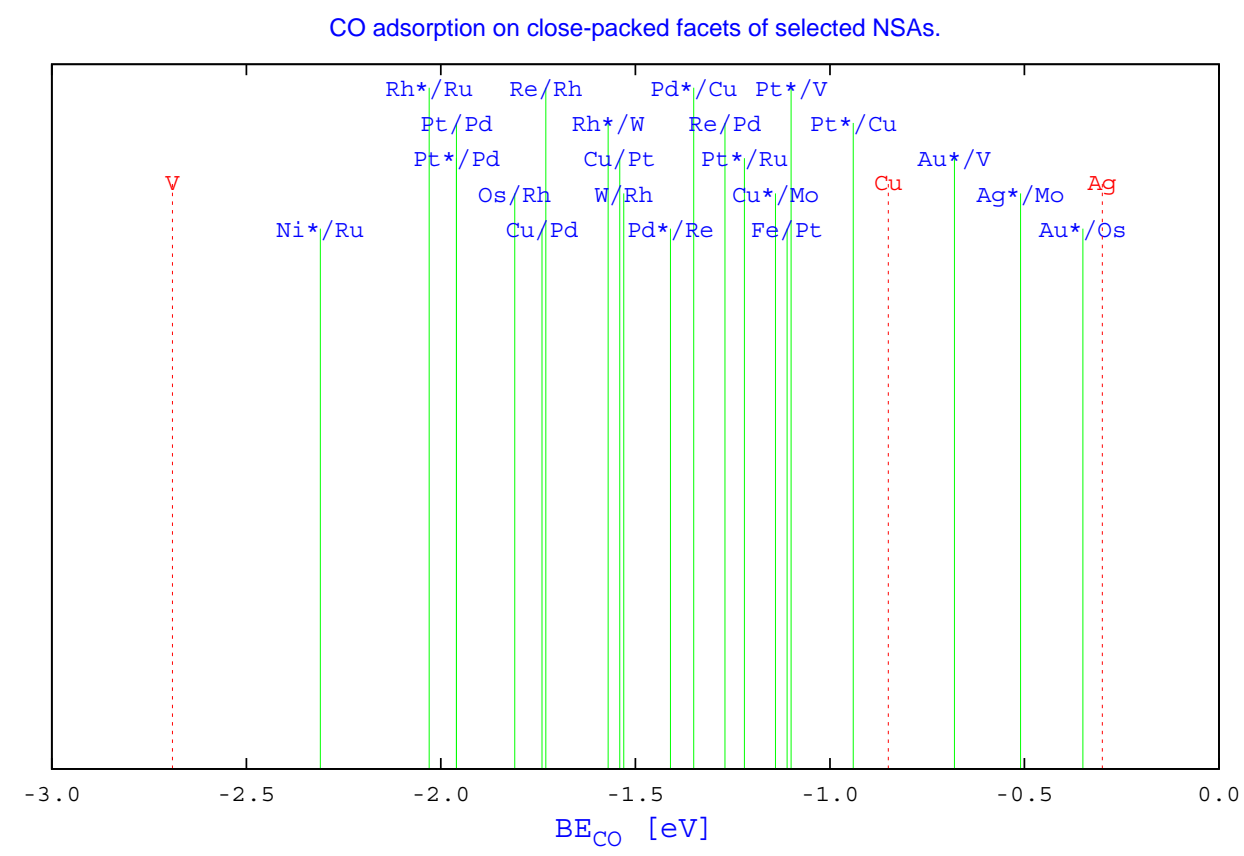

Figure $7 \mathrm{CO}$ adsorption on selected NSAs (sub-surface alloys and overlayers). 
O adsorption on close-packed facets of selected NSAs.

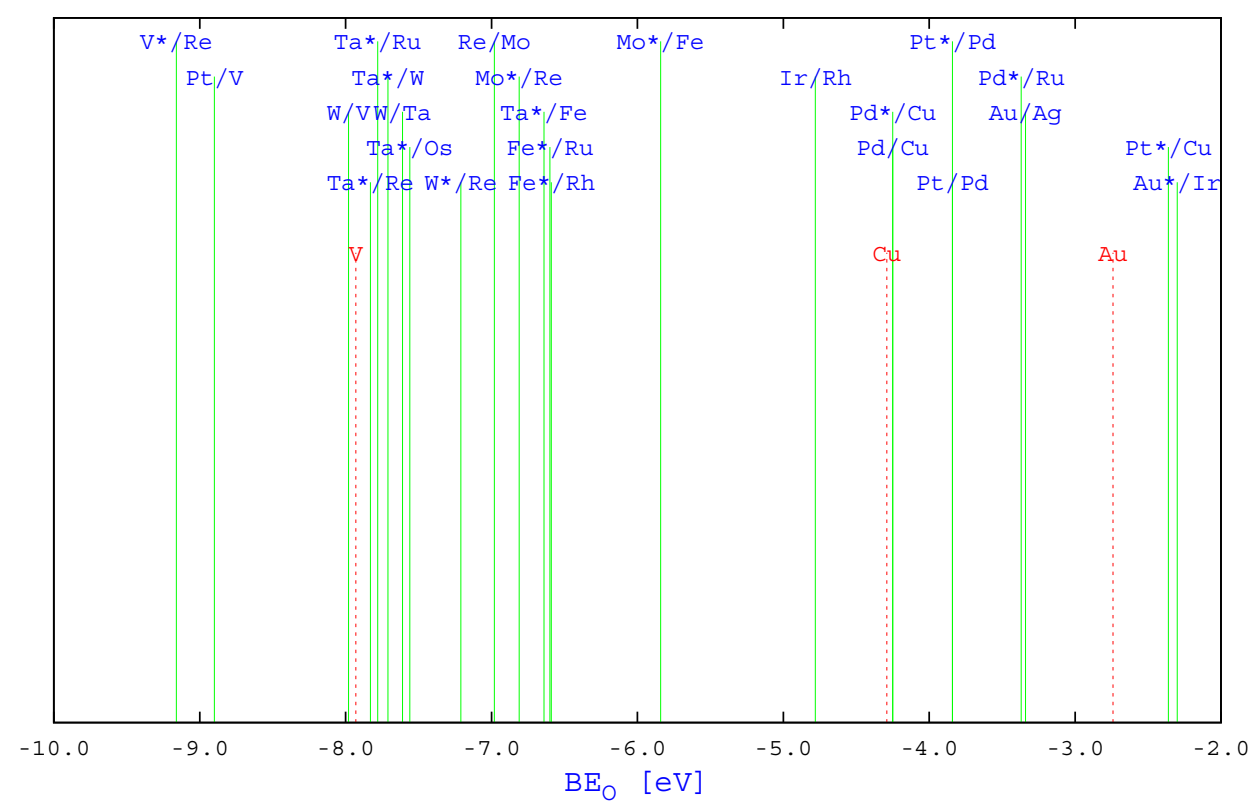

Figure 80 adsorption on selected NSAs (sub-surface alloys and overlayers).

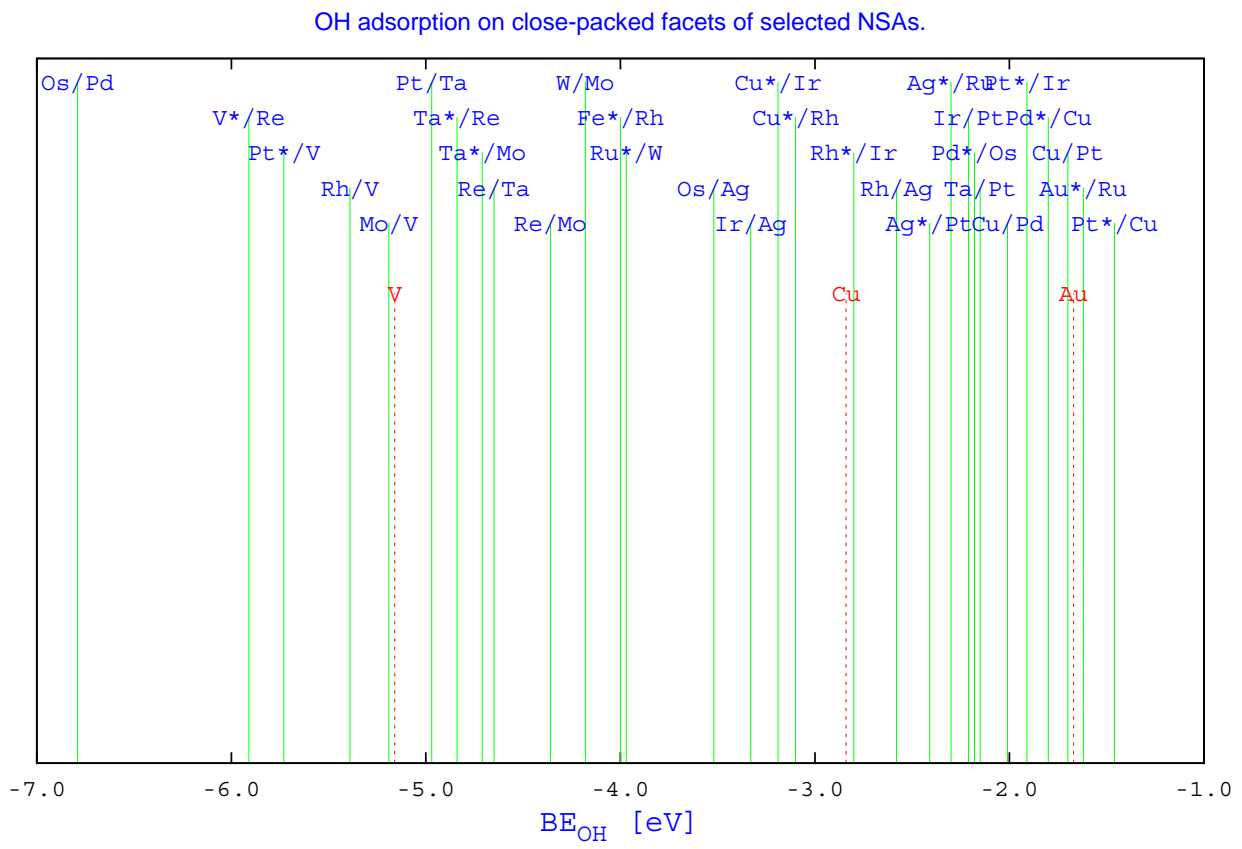

Figure 9 OH adsorption on selected NSAs (sub-surface alloys and overlayers). 


\subsection{Kinetic Studies for WGS on selected NSAs}

Our previous studies have identified $\mathrm{BE}_{\mathrm{CO}}$ as one of the two important descriptors (the other being the difficulty of $\mathrm{H}_{2} \mathrm{O}$ activation) of LWGS activity on transition metals. $\mathrm{Cu}$ combines a medium strength of $\mathrm{CO}$ binding with a rather facile $\mathrm{H}_{2} \mathrm{O}$ activation thereby providing an optimal balance; our endeavor was to find an NSA that can do better than $\mathrm{Cu}$. We focus on NSAs that bind $\mathrm{CO}, \mathrm{OH}$ and $\mathrm{O}$ similarly or less strongly than $\mathrm{Cu}$ for potentially satisfying both of the aforementioned criteria characterizing efficient LWGS catalysis. Detailed DFT studies on the thermochemistry and kinetics of $\mathrm{H}_{2} \mathrm{O}$ activation were undertaken on promising NSAs. There were several strategies available to select this set: One possibility was to select NSAs that are "survivors" in the presence of $\mathrm{CO}, \mathrm{O}$ and $\mathrm{OH}$ individually (Figure 6). On application of this criterion we discovered 40 systems that satisfy these requirements. Another approach would be focus on the $\mathrm{CO}, \mathrm{O}$ and $\mathrm{OH} \mathrm{BEs}$ and select systems that bind these species weakly and are hence likely to be better LWGS catalysts. Various such alternative screener "meshes" (similar to the ones portrayed in Figure 6) can be envisioned and dogmatic adherence to any one of these criteria would be an overly strict condition, in our opinion, and a combination of approaches was warranted.

Previous theoretical calculations for WGS had identified $\mathrm{H}_{2} \mathrm{O}$ activation (more specifically the step $\mathrm{H}_{2} \mathrm{O} \rightarrow \mathrm{OH}+\mathrm{H}$ ) as a Rate Determining Step (RDS) on a variety of TMs. In our quest to identify catalyst that would allow facile water activation we evaluated the minimum energy pathway (MEP) and hence the activation energy for this step on a set of pure metals ( $\mathrm{Cu}, \mathrm{Ag}, \mathrm{Au}, \mathrm{Pt}$ and $\mathrm{Ir}$ ) and promising NSA catalysts: this included the Pt-exposing overlayers $\mathrm{Pt} / \mathrm{Pd}, \mathrm{Pt}^{*} / \mathrm{Au}, \mathrm{Pt} / \mathrm{Ir}$ and $\mathrm{Pt} * / \mathrm{Ru}, \mathrm{Pt}^{*} / \mathrm{Rh}$ and also the sub-surface alloys $\mathrm{Cu} / \mathrm{Pt}$ and $\mathrm{Cu} / \mathrm{Pd}$. Sulfur poisoning is a potential concern for WGS catalyst and hence the S-resistance of these catalyst was also studied: several systems were found that bind $\mathrm{S}$ weaker than $\mathrm{Cu}$ the current WGS catalyst yet provide facile $\mathrm{H}_{2} \mathrm{O}$ activation. 
Specifically, the $\mathrm{Cu} / \mathrm{Pt}$ catalyst was the most promising improved WGS catalyst to be identified during this project ${ }^{11}$. $\mathrm{Cu} / \mathrm{Pt}$ shows an enhancement of $\mathrm{Cu}$ concentration in the first sub-surface of the $\mathrm{Pt}$ host and this system has been shown to be thermodynamically stable in CO-rich environments and hence CO-induced reconstruction and segregation is not expected in this catalyst. Further, this NSA is able to easily dissociate water and binds the products of $\mathrm{H}_{2} \mathrm{O}$ dissociation $(\mathrm{OH}+\mathrm{H})$ weaker than $\mathrm{Cu}$ (Figure 10). The formate intermediate (HCOO) is known to be rather stable on conventional Cu-based WGS catalysts and high coverages of this species can poison the catalyst surface and impair catalyst activity. CO is another poison implicated in WGS models, for instance on Pt. The Cu/Pt NSA that we identified binds formate weaker than $\mathrm{Cu}$ and $\mathrm{CO}$ weaker than Pt thereby making it less prone to site-blocking and poisoning by these species. Sulfur adsorption calculations indicate this catalyst possesses resistance to S-poisoning comparable to that of conventional $\mathrm{Cu}$. Our assertions of the superior nature of the $\mathrm{Cu} / \mathrm{Pt}$ catalyst were experimentally verified by collaborators using a variety of techniques including XPS, TPD and STM ${ }^{11}$.

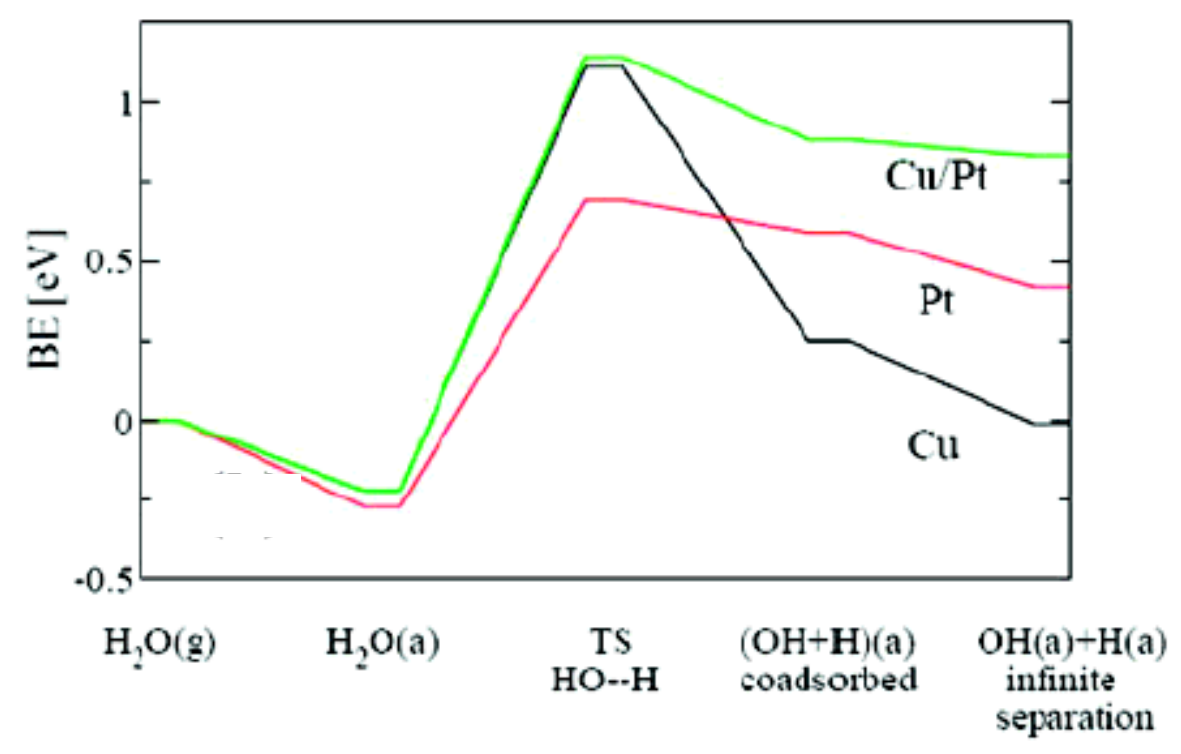

Figure 10 Potential energy surface (PES) for $\mathrm{H}_{2} \mathrm{O}$ activation on $\mathrm{Pt}, \mathrm{Cu}$, and $\mathrm{Cu} / \mathrm{Pt}$ NSA (from ${ }^{11}$ ). 


\section{Conclusions / Summary of accomplishments}

The Binding Energies of WGS relevant intermediates ( $\mathrm{CO}, \mathrm{O}$ and $\mathrm{OH}$ ) were evaluated on 17 catalytically relevant close-packed transition metal (TM) surfaces. A large number of bimetallic alloys can be synthesized from this set of 17 TMs and hence we employed several "screening" criteria to identify promising bimetallic NSAs deserving further study. Our main criterion was the thermodynamic stability of these NSAs, both in vacuo and also in the presence of the stronger-binding-adsorbates to be expected in significant coverages under typical WGS reaction conditions. A total of 40 NSAs were found to survive the strict criteria of being stable under the influence of all three species $\mathrm{CO}, \mathrm{O}$ and $\mathrm{OH}$. DFT calculations using the first-principles code DACAPO were performed for the adsorption of $\mathrm{CO}, \mathrm{O}$ and $\mathrm{OH}$ on the most-stable, close-packed facets of these NSA-catalysts. The resultant BE-database was utilized for guiding the targeted discovery of novel high-activity WGS catalysts. The $\mathrm{Cu} / \mathrm{Pt}$ bimetallic subsurface alloy was identified as a promising WGS catalyst that combines the goals of high activity, stability against reconstructions and poison resistance.

\section{Plans for future work}

The funding for the current project got exhausted in the Fall of 2007 and hence further calculations could not be continued since. Analogous to the $\mathrm{Cu} / \mathrm{Pt}$ system (that was studied in detail during this project) several other NSA-based bimetallic catalysts have been identified as potentially promising WGS catalysts. Detailed kinetic calculations for the elementary steps of WGS (with an emphasis on $\mathrm{H}_{2} \mathrm{O}$ activation) on such a set of promising systems is warranted with the objective of expanding our set of thermodynamically-stable, highly active, poison-resistant WGS catalysts. 


\section{Graphical Material List / Table of Figures}

Figure 1 Strength of CO binding on monometallic transition-metal surfaces................. 10

Figure 2 Strength of $\mathrm{O}$ binding on monometallic transition-metal surfaces..................... 10 Figure 3 Strength of hydroxyl $(-\mathrm{OH})$ binding on monometallic transition-metal surfaces.

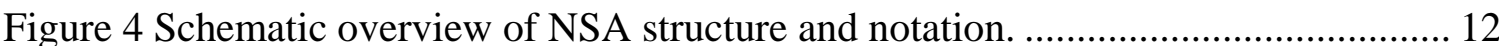

Figure 5: The "CO screener plot": Identification of NSAs stable in a CO rich environment:

Figure 6 Employment of a cascade of screening criteria for the reduction of the set of

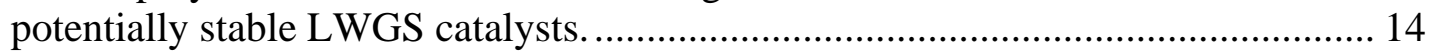

Figure $7 \mathrm{CO}$ adsorption on selected NSAs (sub-surface alloys and overlayers).............. 15

Figure $8 \mathrm{O}$ adsorption on selected NSAs (sub-surface alloys and overlayers)................. 16

Figure $9 \mathrm{OH}$ adsorption on selected NSAs (sub-surface alloys and overlayers).............. 16 Figure 10 Potential energy surface (PES) for $\mathrm{H}_{2} \mathrm{O}$ activation on $\mathrm{Pt}, \mathrm{Cu}$, and $\mathrm{Cu} / \mathrm{Pt} \mathrm{NSA}$

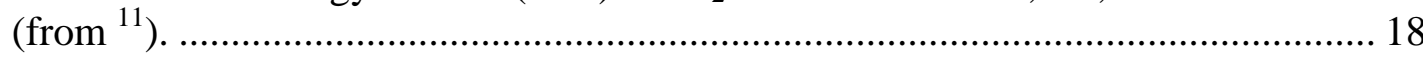




\section{Selected Literature References}

(1) Grenoble, D. C.; Estadt, M. M.; Ollis, D. F. J. Catal. 1981, 67, 90.

(2) Ovensen, C. V.; Stoltze, P.; Noerskov, J. K.; Campbell, C. T. J. Catal. 1992, 134, 445.

(3) Campbell, C. T.; Daube, K. A. J. Catal. 1987, 104, 109.

(4) Hammer, B.; Hansen, L. B.; Nørskov, J. K. Phys. Rev. B: Condens. Matter Mater. Phys. 1999, 59, 7413.

(5) Greeley, J.; Nørskov, J. K.; Mavrikakis, M. Annu. Rev. Phys. Chem. 2002, 53, 319.

(6) Beutl, M.; Lesnik, J.; Rendulic, K. D.; Hirschl, R.; Eichler, A.; Kresse, G.; Hafner, J. Chem. Phys. Lett. 2001, 342, 473.

(7) Zhou, S. G.; McIlwrath, K.; Jackson, G.; Eichhorn, B. J. Am. Chem. Soc. 2006, 128, 1780.

(8) Lang, H.; Maldonado, S.; Stevenson, K. J.; Chandler, B. D. J. Am. Chem. Soc. 2004, 126, 12949.

(9) Ruban, A. V.; Skriver, H. L.; Nørskov, J. K. Phys. Rev. B 1999, 59, 15990.

(10) Greeley, J.; Mavrikakis, M. Nat. Mater. 2004, 3, 810.

(11) Knudsen, J.; Nilekar, A. U.; Vang, R. T.; Schnadt, J.; Kunkes, E. L.;

Dumesic, J. A.; Mavrikakis, M.; Besenbacher, F. J. Am. Chem. Soc. 2007, 129, 6485.

\section{List of Published Journal Articles}

1. “A Cu/Pt Near-Surface Alloy for improved water-gas shift catalysis”, Knudsen, J.; Nilekar, A. U.; Vang, R. T.; Schnadt, J.; Kunkes, E. L.; Dumesic, J. A.; Mavrikakis, M.; Besenbacher, F. J. Am. Chem. Soc. 2007, 129, 6485.

\section{Awards/Distinctions for the PI}

1. Editorial Board of Surface Science

2. Editorial Board of Annual Review of Chemical \& Biomolecular Engineering

3. Samuel C. Johnson Distinguished Fellowship.

4. Visiting Professor, Department of Chemical Engineering, Technical University of Denmark, Lyngby, Denmark (Fall 2006).

5. Featured in: Chemical \& Engineering News, Mar. 24, 2008, Vol. 86, Issue 12, p. 4041. (http://pubs.acs.org/isubscribe/journals/cen/86/i12/html/8612scic.html).

6. Featured in NERSC News (March 2007): http://www.nersc.gov/news/nerscnews/NERSCNews_2007_03.pdf

7. Member of the Advising Board for the Center for Atomic-scale Materials Design (CAMD), Department of Physics, Technical University of Denmark, Lyngby, Denmark (1/07- ). 


\section{Students supported by this grant}

Partial support for Rahul Nabar and Anand Nilekar

\section{List of Acronyms and Abbreviations}

$\begin{array}{ll}\text { LWGS } & \text { Low Temperature Water Gas Shift } \\ \text { WGS } & \text { Water Gas Shift } \\ \text { NSA } & \text { Near Surface Alloy } \\ \text { DFT } & \text { Density Functional Theory } \\ \text { BE } & \text { Binding Energy } \\ \text { GGA } & \text { Generalized Gradient Approximation } \\ \text { PW91 } & \text { Perdew-Wang 91 } \\ \text { TM } & \text { Transition Metal } \\ \text { RDS } & \text { Rate Determining Step } \\ \text { MEP } & \text { Minimum Energy Pathway } \\ \text { NEB } & \text { Nudged Elastic Band } \\ \text { XPS } & \text { X-ray photoelectron spectroscopy } \\ \text { TPD } & \text { Temperature Programmed Desorption } \\ \text { STM } & \text { Scanning Tunneling Microscopy } \\ \text { TS } & \text { Transition State } \\ \text { PES } & \text { Potential Energy Surface }\end{array}$




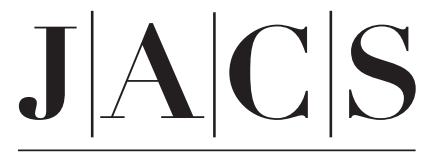

A R T I C L E S

Published on Web 05/01/2007

\title{
A Cu/Pt Near-Surface Alloy for Water-Gas Shift Catalysis
}

\author{
Jan Knudsen, ${ }^{\dagger}$ Anand U. Nilekar, ${ }^{\ddagger}$ Ronnie T. Vang, ${ }^{\dagger}$ Joachim Schnadt, ${ }^{\dagger}$ \\ Edward L. Kunkes, ${ }^{\ddagger}$ James A. Dumesic, ${ }^{\ddagger}$ Manos Mavrikakis, ${ }^{,}, \neq$and \\ Flemming Besenbacher ${ }^{*}, \dagger$ \\ Contribution from the Interdisciplinary Nanoscience Center (iNANO) and Department of Physics \\ and Astronomy, University of Aarhus, DK-8000 Aarhus C, Denmark, and Department of \\ Chemical and Biological Engineering, University of Wisconsin-Madison, \\ Madison, Wisconsin 53706 \\ Received January 5, 2007; E-mail: manos@engr.wisc.edu; fbe@inano.dk
}

\begin{abstract}
The primary route to hydrogen production from fossil fuels involves the water-gas shift (WGS) reaction, and an improvement in the efficiency of WGS catalysts could therefore lead to a major leap forward in the realization of hydrogen economy. On the basis of a combination of high-resolution scanning tunneling microscopy, X-ray photoelectron spectroscopy, and density functional theory (DFT) calculations, we suggest the existence of a new thermodynamically stable Cu/Pt near-surface alloy (NSA). Temperature-programmed desorption and DFT reveal that this Cu/Pt NSA binds CO significantly more weakly than does Pt alone, thereby implying a considerable reduction in the potential for $\mathrm{CO}$ poisoning of the Cu/Pt NSA surface as compared to that of pure Pt. In addition, DFT calculations show that this $\mathrm{Cu} / \mathrm{Pt} \mathrm{NSA}$ is able to activate $\mathrm{H}_{2} \mathrm{O}$ easily, which is the rate-determining step for the WGS on several metal surfaces, and, at the same time, to bind the products of that reaction and formate intermediates rather weakly, thus avoiding possible poisoning of the catalyst surface. The Cu/Pt NSA is thus a promising candidate for an improved WGS catalyst.
\end{abstract}

\section{Introduction}

The water-gas shift (WGS) reaction, in which carbon monoxide $(\mathrm{CO})$ reacts with water $\left(\mathrm{H}_{2} \mathrm{O}\right)$ to form carbon dioxide $\left(\mathrm{CO}_{2}\right)$ and hydrogen $\left(\mathrm{H}_{2}\right),{ }^{1}$ is used extensively in the conversion of fossil fuel to hydrogen. In particular, WGS removes residual $\mathrm{CO}$ from reformate hydrogen gas, which is important when hydrogen is used as a fuel for low-temperature fuel cells; the performance of such fuel cells is very sensitive to $\mathrm{CO}$ impurities because of $\mathrm{CO}$ poisoning of the Pt-based anode. ${ }^{2-4}$

The WGS reaction is slightly exothermic $(\sim 40 \mathrm{~kJ} / \mathrm{mol})$, and therefore low reaction temperatures push the equilibrium toward hydrogen production, while high reaction temperatures provide faster kinetics. To deal with these two opposing temperature effects, large-scale industrial plants often use a two-step WGS reactor in which the feed gas is led through a high-temperature WGS reactor and then a low-temperature recator. ${ }^{5}$ However, such a two-step process is not a viable solution for small-scale applications such as on-board reformers in hydrogen fuel cellpowered automobiles. Consequently, it is very important to develop new WGS catalysts with high activity at lower

$\dagger$ University of Aarhus.

$\doteqdot$ University of Wisconsin-Madison.

(1) Ovesen, C. V.; Stoltze, P.; Norskov, J. K.; Campbell, C. T. J. Catal. 1992, $134,445-468$.

(2) Handbook of Fuel Cells: Fundamentals, Technology, Applications; Wiley: West Sussex, UK, 2003.

(3) Oetjen, H. F.; Schmidt, V. M.; Stimming, U.; Trila, F. J. Electrochem. Soc. 1996, $143,3838-3842$

(4) Greeley, J.; Mavrikakis, M. Catal. Today 2006, 111, 52-58.

(5) Somorjai, G. Introduction to Surface Chemistry and Catalysis; John Wiley \& Sons: New York, 1994.

10.1021/ja0700855 CCC: $\$ 37.00$ @ 2007 American Chemical Society temperatures than the presently used low-temperature $\mathrm{Cu}$-based WGS catalysts.

Transition metal alloys are very often superior to pure transition metals as the active materials in heterogeneous catalysis. ${ }^{6}$ During the past century, the development of alloy catalysts has almost exclusively been accomplished by trial and error. Recent advances in both experimental and theoretical methods, however, have facilitated the development of new and improved alloy catalysts based on fundamental surface science and first-principles studies. ${ }^{7-10}$ These advances continue to pave the way for a new era in which promising catalysts may be identified directly from first principles. , $^{81-13}$

Here, we report on a novel $\mathrm{Cu} / \mathrm{Pt}$ near-surface alloy (NSA) with an enhanced $\mathrm{Cu}$ concentration in the first subsurface layer of the Pt host, which is shown to be a promising candidate for an improved low-temperature WGS catalyst. From an interplay of scanning tunneling microscopy (STM), X-ray photoelectron

(6) Sinfelt, J. Bimetallic Catalysts: Discoveries, Concepts and Applications; Wiley: New York, 1983.

(7) Besenbacher, F.; Chorkendorff, I.; Clausen, B. S.; Hammer, B.; Molenbroek, A. M.; Norskov, J. K.; Stensgaard, I. Science 1998, 279, 1913-1915.

(8) Greeley, J.; Mavrikakis, M. Nat. Mater. 2004, 3, 810-815.

(9) Vang, R. T.; Honkala, K.; Dahl, S.; Vestergaard, E. K.; Schnadt, J.; Laegsgaard, E.; Clausen, B. S.; Norskov, J. K.; Besenbacher, F. Nat. Mater 2005, 4, 160-162.

(10) Jacobsen, C. J. H.; Dahl, S.; Clausen, B. S.; Bahn, S.; Logadottir, A ; Norskov, J. K. J. Am. Chem. Soc. 2001, 123, 8404-8405.

(11) Zhang, J. L.; Vukmirovic, M. B.; Xu, Y.; Mavrikakis, M.; Adzic, R. R. Angew. Chem., Int. Ed. 2005, 44, 2132-2135.

(12) Zhang, J. L.; Vukmirovic, M. B.; Sasaki, K.; Nilekar, A. U.; Mavrikakis, M.; Adzic, R. R. J. Am. Chem. Soc. 2005, 127, 12480-12481.

(13) Greeley, J.; Jaramillo, T. F.; Bonde, J.; Chorkendorff, I. B.; Norskov, J. K. Nat. Mater. 2006, 5, 909-913. 
spectroscopy (XPS), and density functional theory (DFT) calculations, we show that a thermodynamically stable $\mathrm{Cu} / \mathrm{Pt}$ NSA, with $\mathrm{Cu}$ preferentially located in the first subsurface layer, is formed upon evaporation of 1 monolayer (ML) of $\mathrm{Cu}$ onto $\mathrm{Pt}(111)$ at $800 \mathrm{~K}$. Temperature-programmed desorption (TPD) and DFT studies show that the potential for $\mathrm{CO}$ poisoning of the $\mathrm{Cu} / \mathrm{Pt}$ NSA is reduced compared to that of pure Pt. Finally, we use DFT to analyze trends in catalytic activation of water, which is the rate-determining step for the WGS on several metal surfaces, and the binding of formate, a common spectator species that blocks sites on $\mathrm{Cu}$ WGS catalysts. By combining these results, we propose that the $\mathrm{Cu} / \mathrm{Pt}(111)$ NSA possesses a higher WGS activity than the pure $\mathrm{Cu}(111)$ surface of the industrially used WGS catalyst.

\section{Methods}

The STM experiments were performed in an ultra-high-vacuum system with a base pressure of $\sim 10^{-10}$ Torr, equipped with the homebuilt Aarhus STM. ${ }^{14}$ A Pt(111) crystal was cleaned with cycles of $\mathrm{Ar}$ ion sputtering $(1.0 \mathrm{keV}, 10 \mathrm{~min})$ followed by annealing to $1000 \mathrm{~K}$ for $3 \mathrm{~min}$. These cycles were repeated until no contamination of the crystal could be detected with the STM. Cu was deposited either by a homebuilt evaporator consisting of a piece of $\mathrm{Cu}$ placed in a resistively heated tungsten crucible or with a mini e-beam evaporator (Oxford Applied Research). Both evaporators were calibrated from STM pictures of $\mathrm{Cu}$ evaporated onto $\mathrm{Pt}(111)$ at room temperature. All XPS measurements of $\mathrm{Cu} 3 \mathrm{~s}$ were performed at the SX700 beamline located at the Aarhus Storage Ring in Denmark (ASTRID), with $h v=205 \mathrm{eV}$ in normal emission. A fixed $100 \mathrm{~mm}$ mean radius analyzer (VG-CLAM2) was used in all experiments. The TPD measurements were obtained using a Balzers quadrupole mass spectrometer, after the crystal was exposed to $10 \mathrm{~L}$ of $\mathrm{CO}$ at $166 \mathrm{~K}$, and with a heating rate of $2 \mathrm{~K} / \mathrm{s}$.

The self-consistent DFT calculations were carried out using the DACAPO ${ }^{15,16}$ total-energy code with ultrasoft pseudopotentials, plane waves with kinetic energies of up to $25 \mathrm{Ry}$, and 6 or $18 k$-points in the first Brillouin zone for (111) facets of four-layer metal slabs with $3 \times$ 3 and $2 \times 2$ surface unit cells, respectively. The equivalent of five layers of vacuum was used to separate periodic images of metal slabs in the $z$-direction of the unit cell. Adsorption is allowed on only one of the two exposed surfaces, and the electrostatic potential is adjusted accordingly. ${ }^{17,18}$ All $\mathrm{CO}$ and formate (HCOO) binding energy calculations were performed at a coverage of $1 / 9 \mathrm{ML}$ on a $3 \times 3$ surface unit cell, whereas a $2 \times 2$ unit cell was used for the calculation of the activation energy barrier for $\mathrm{H}_{2} \mathrm{O}$ dissociation. Ionic cores were described by ultrasoft pseudopotentials, ${ }^{19}$ and the Kohn-Sham oneelectron valence states were expanded in a basis of plane waves with kinetic energy below $25 \mathrm{Ry}$. The exchange-correlation energy and potential were described self-consistently within the generalized gradient approximation (GGA-PW91). ${ }^{20,21}$ The self-consistent PW91 density was determined by iterative diagonalization of the Kohn-Sham Hamiltonian, Fermi population of the Kohn-Sham states $\left(k_{\mathrm{B}} T=0.1 \mathrm{eV}\right)$, and Pulay mixing of the resulting electronic density. ${ }^{22}$ All total energies have been extrapolated to $k_{\mathrm{B}} T=0 \mathrm{eV}$. Zero-point energy effects were not considered in the reported results. Unless otherwise specified, all

(14) Laegsgaard, E.; Besenbacher, F.; Mortensen, K.; Stensgaard, I. J. Microsc. (Oxford) 1988, 152, 663-669.

(15) Hammer, B.; Hansen, L. B.; Nørskov, J. K. Phys. Rev. B 1999, 59, 74137421.

(16) Greeley, J.; Nørskov, J. K.; Mavrikakis, M. Annu. Rev. Phys. Chem. 2002, $53,319-348$.

(17) Neugebauer, J.; Scheffler, M. Phys. Rev. B 1992, 46, 16067-16080.

(18) Bengtsson, L. Phys. Rev. B 1999, 59, 12301-12304.

(19) Vanderbilt, D. Phys. Rev. B 1990, 41, 7892-7895.

(20) Perdew, J. P.; Chevary, J. A.; Vosko, S. H.; Jackson, K. A.; Pederson, M. R.; Singh, D. J.; Fiolhais, C. Phys. Rev. B 1992, 46, 6671-6687.

(21) White, J. A.; Bird, D. M. Phys. Rev. B 1994, 50, 4954-4957.

(22) Kresse, G.; Furthmuller, J. Comput. Mater. Sci. 1996, 6, 15-50.
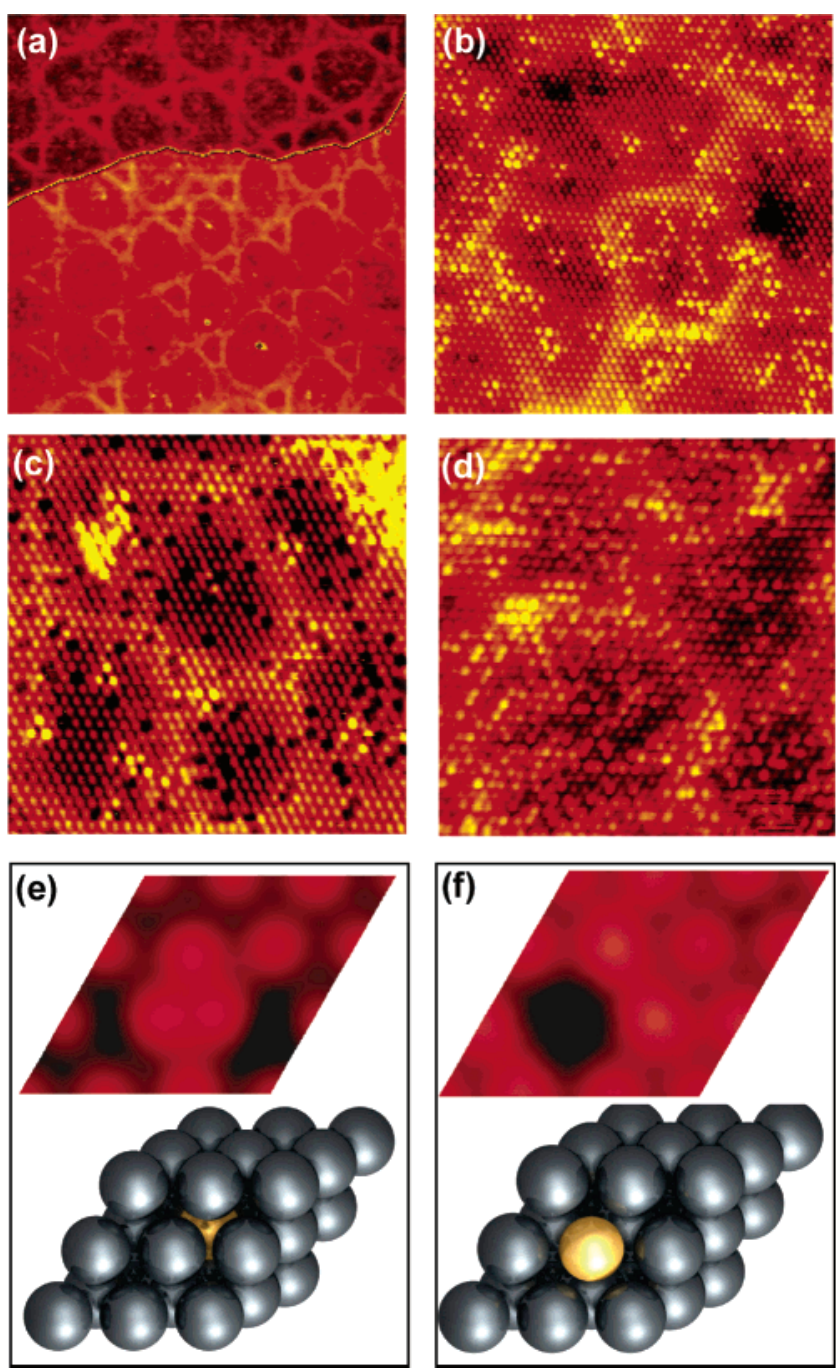

Figure 1. (a-d) STM images of $\mathrm{Cu} / \mathrm{Pt}(111)$ surface alloys. (a,b) Surface prepared by evaporation of $1 \mathrm{ML}$ of $\mathrm{Cu}$ onto $\mathrm{Pt}(111)$ at $800 \mathrm{~K}$ (image sizes are $631 \times 631 \AA^{2}$ and $132 \times 132 \AA^{2}$, respectively). (c) Surface prepared by the evaporation of $1 \mathrm{ML}$ of $\mathrm{Cu}$ onto $\mathrm{Pt}(111)$ followed by $1 \mathrm{ML}$ of $\mathrm{Pt}$ at room temperature $\left(100 \times 100 \AA^{2}\right)$. (d) The surface in (c) after postannealing at $773 \mathrm{~K}\left(100 \times 100 \AA^{2}\right)$. (e,f) Simulated STM images of a $\mathrm{Cu}$ atom (gold spheres) in the first subsurface layer (e) or in the topmost layer (f) of a $\mathrm{Pt}(111)$ substrate (gray spheres) within the framework of a $3 \times 3$ surface unit cell.

degrees of freedom for the top two layers of slab atoms and for all adsorbate atoms were relaxed. Transition states for $\mathrm{H}_{2} \mathrm{O}$ dissociation were located with the "climbing-image nudged elastic band" method. ${ }^{23}$

\section{Results and Discussion}

When $\mathrm{Cu}$ was evaporated onto a $\operatorname{Pt}(111)$ crystal, the STM images clearly indicated the formation of an NSA. ${ }^{8}$ In particular, Figure 1a shows an STM image of a Pt(111) surface after evaporation of $1 \mathrm{ML}$ of $\mathrm{Cu}$ at a substrate temperature of 800 $\mathrm{K}$. The surface displays a network of bright rings ordered in a nonperfect hexagonal symmetry with a periodicity of $\sim 100 \AA$. These bright lines are speculated to be stress-induced boundaries between atoms sitting in face-centered cubic (fcc) and hexagonal close-packed (hcp) sites. ${ }^{24,25}$ Atomically resolved images (Figure

(23) Henkelman, G.; Jónsson, H. J. Chem. Phys. 2000, 113, 9978-9985.

(24) Holst, B.; Nohlen, M.; Wandelt, K.; Allison, W. Surf. Sci. 1997, 377, 891894.

(25) Holst, B.; Nohlen, M.; Wandelt, K.; Allison, W. Phys. Rev. B 1998, 58, R10195-R10198. 
1b) reveal that the surface atoms appear with different corrugations in the STM images, which serves as a clear indication of NSA formation. In the topmost surface layer, we did not find any dislocations visible to the STM. Therefore, we conclude that the bright lines observed in the STM images are related to subsurface atoms changing between stacking of fcc and hcp sites.

A ring structure very similar to the one described above was observed when we evaporated $1 \mathrm{ML}$ of $\mathrm{Cu}$ onto $\mathrm{Pt}(111)$, followed by evaporation of $1 \mathrm{ML}$ of $\mathrm{Pt}$ at room temperature, where both $\mathrm{Cu}$ and $\mathrm{Pt}$ grow as adlayers. As can be seen in Figure 1c, similar bright lines show up in the STM images of this "sandwich" structure. However, some atoms in the topmost layer are imaged as depressions, which we did not observe in the original ring structure. These dark spots disappear upon annealing to $773 \mathrm{~K}$ (Figure 1d), in which case we end up with a structure almost identical to the ring structure of Figure $1 \mathrm{~b}$.

The wave functions derived from DFT calculations were used to calculate STM images ${ }^{26}$ by employing the Tersoff-Hamann approach. ${ }^{27}$ These calculations were performed for a number of configurations with $\mathrm{Cu}$ located on the surface and/or subsurface of $\mathrm{Pt}(111)$. The simulated STM image shown in Figure 1e represents a single $\mathrm{Cu}$ atom in the second layer of the $\operatorname{Pt}(111)$ slab; this image is in qualitatively good agreement with the trimers of bright atoms observed by STM between the rings in Figure 1b. The simulated STM image of a surface $\mathrm{Cu}$ atom in a $\operatorname{Pt}(111)$ substrate (Figure 1f) shows a distinct depression, which strongly suggests that the dark spots in the sandwich structure are $\mathrm{Cu}$ atoms incorporated in the topmost layer. These depressions are not observed in the ring structure, and we therefore conclude that evaporation of $1 \mathrm{ML}$ of $\mathrm{Cu}$ onto $\mathrm{Pt}(111)$ at $800 \mathrm{~K}$ leads to the formation of NSA without $\mathrm{Cu}$ atoms in the surface layer.

To further investigate the formation of the subsurface $\mathrm{Cu} / \mathrm{Pt}$ alloy, we used DFT calculations to determine the thermodynamics and energetic aspects of its formation kinetics. From calculations on a $3 \times 3$ surface unit cell of a seven-layer Pt(111) slab, we found that the activation energy barrier for both $\mathrm{Pt}$ vacancy formation in $\mathrm{Pt}(111)$ and $\mathrm{Cu}$ adatom diffusion from the surface of $\mathrm{Pt}(111)$ into a Pt vacancy in $\mathrm{Pt}(111)$ is less than $3 \mathrm{eV}$. Barriers of this magnitude can be surmounted at $800 \mathrm{~K}$, the sample temperature during the original $\mathrm{Cu}$ deposition, and thus we expect a structure in thermodynamic equilibrium. We analyzed the relative stability of $\mathrm{Cu}$ atoms in various layers of the seven-layer $\operatorname{Pt}(111)$ slab, now allowing for relaxation of the top five layers. By replacing one or two of the Pt atoms in the slab with $\mathrm{Cu}$ atoms, either in the top (i.e., surface) layer or in the second, third, or fourth layer of the slab, we were able to determine the relative energetics as a function of $\mathrm{Cu}$ coverage (1/4 or $1 / 2 \mathrm{ML}$, respectively). We found that $1 / 4 \mathrm{ML}$ of $\mathrm{Cu}$ is more stable when located in the second, third, or fourth layer of the slab by $0.48,0.34$, or $0.35 \mathrm{eV}$, respectively, than when $\mathrm{Cu}$ is located in the surface layer. Furthermore, these trends in the relative energetics of $\mathrm{Cu}$ in $\mathrm{Pt}(111)$ remain practically invariant when the $\mathrm{Cu}$ coverage is increased to $1 / 2 \mathrm{ML}$ or when a $\mathrm{Pt}(100)$ facet is considered instead of the $\mathrm{Pt}(111)$ facet. Studies of $\mathrm{Cu}$ on/in facets of $\mathrm{Pt}$ other than the (111) facet may be

(26) Bollinger, M. V.; Lauritsen, J. V.; Jacobsen, K. W.; Norskov, J. K.; Helveg, S.; Besenbacher, F. Phys. Rev. Lett. 2001, 87, 196803.

(27) Tersoff, J.; Hamann, D. R. Phys. Rev. B 1985, 31, 805-813. relevant to realistic catalyst nanoparticles, naturally exposing a mixture of crystallographic facets. In all cases, the relative stability of $\mathrm{Cu}$ in the third and fourth layers of the Pt slab appears to be converged to what we consider to be the stability of $\mathrm{Cu}$ in bulk Pt. These results show that a significant driving force causes $\mathrm{Cu}$ to diffuse into the Pt slab rather than staying in the surface layer, and that the thermodynamics of $\mathrm{Cu}-\mathrm{Pt}$ alloy dictate a preferential occupation of sites within the first subsurface layer of $\operatorname{Pt}(111)$.

This conclusion was verified by XPS measurements, which showed a $70 \%$ attenuation of the $\mathrm{Cu} 3$ s peak when an overlayer of $\mathrm{Cu}$ on $\mathrm{Pt}(111)$ was flashed to $800 \mathrm{~K}$, while the peak intensity was not attenuated any further when the sample was kept at $800 \mathrm{~K}$ for longer periods.

Finally, our DFT results for $\mathrm{Cu}$ on/in $\mathrm{Pt}(100)$ indicate trends similar to those established above for $\mathrm{Pt}(111)$, in terms of both the thermodynamics and kinetics of the subsurface alloy formation. If anything, the migration of $\mathrm{Cu}$ to the subsurface of Pt becomes even easier through the more open (100) facet.

A depth profile of $\mathrm{Cu}$ in the $\mathrm{Pt}(111)$ host can be obtained from the DFT-calculated stabilization energies of $\mathrm{Cu}$ in different layers and the XPS data discussed above. The $\mathrm{Cu} 3$ s intensity of the subsurface alloy, $I$, relative to the intensity of the overlayer, $I_{0}$, can be expressed as the following sum, if it is assumed that the $\mathrm{Cu}$ atoms are distributed in a finite number of layers, $N$, close to the surface:

$$
\frac{I}{I_{0}}=\sum_{i=1}^{N} c_{i} \exp \left(-\frac{(i-1) d}{\mu}\right)
$$

Here, $c_{i}$ is the concentration of $\mathrm{Cu}$ in layer $i, \mu$ is the inelastic mean free path of the electron in $\operatorname{Pt}(111)$, and $d$ is the interlayer distance in $\mathrm{Pt}(111)$ since the amount of $\mathrm{Cu}$ in the $\mathrm{Pt}(111)$ host is relatively low. The concentration of $\mathrm{Cu}$ atoms in the surface layer is observed to be zero in the STM, as discussed above, and $c_{1}$ is therefore equal to zero. The DFT calculations show that the relative stability of $\mathrm{Cu}$ converges to the bulk value in the third layer, and $c_{i}$ is therefore assumed to be constant for $i$ $\geq 3$. From a Boltzman distribution, we can determine the relative $\mathrm{Cu}$ concentration in the second layer $\left(c_{2}\right)$ with respect to the bulk value $\left(c_{\text {bulk }}\right)$ :

$$
\begin{aligned}
\frac{c_{2}(\mathrm{Cu})}{c_{\text {bulk }}(\mathrm{Cu})} & =\exp \left(\frac{E_{2}-E_{\text {bulk }}}{k T}\right) \\
& =\exp \left(\frac{0.48 \mathrm{eV}-0.35 \mathrm{eV}}{\left(8.62 \times 10^{-5} \mathrm{eV} / \mathrm{K}\right) \times 800 \mathrm{~K}}\right)=6.6
\end{aligned}
$$

Finally, the sum can be rewritten as

$$
\frac{I}{I_{0}}=0.30=c_{2} \exp \left(\frac{-d}{\mu}\right)+\frac{c_{2}}{6.6} \sum_{i=3}^{N} \exp \left(\frac{-(i-1) d}{\mu}\right)
$$

This equation is solved under the constraint that the total amount of $\mathrm{Cu}$ is fixed to $1 \mathrm{ML}$. The best agreement with the experimentally observed damping is obtained with $0.4 \mathrm{ML}$ of $\mathrm{Cu}$ in the second layer and $0.06 \mathrm{ML}$ of $\mathrm{Cu}$ in layers 3-11.

Having discussed the atomic-scale structure of the $\mathrm{Cu} / \mathrm{Pt}$ NSA, we now turn our attention to its WGS reactivity. First, we use DFT calculations and TPD experiments to probe the strength 

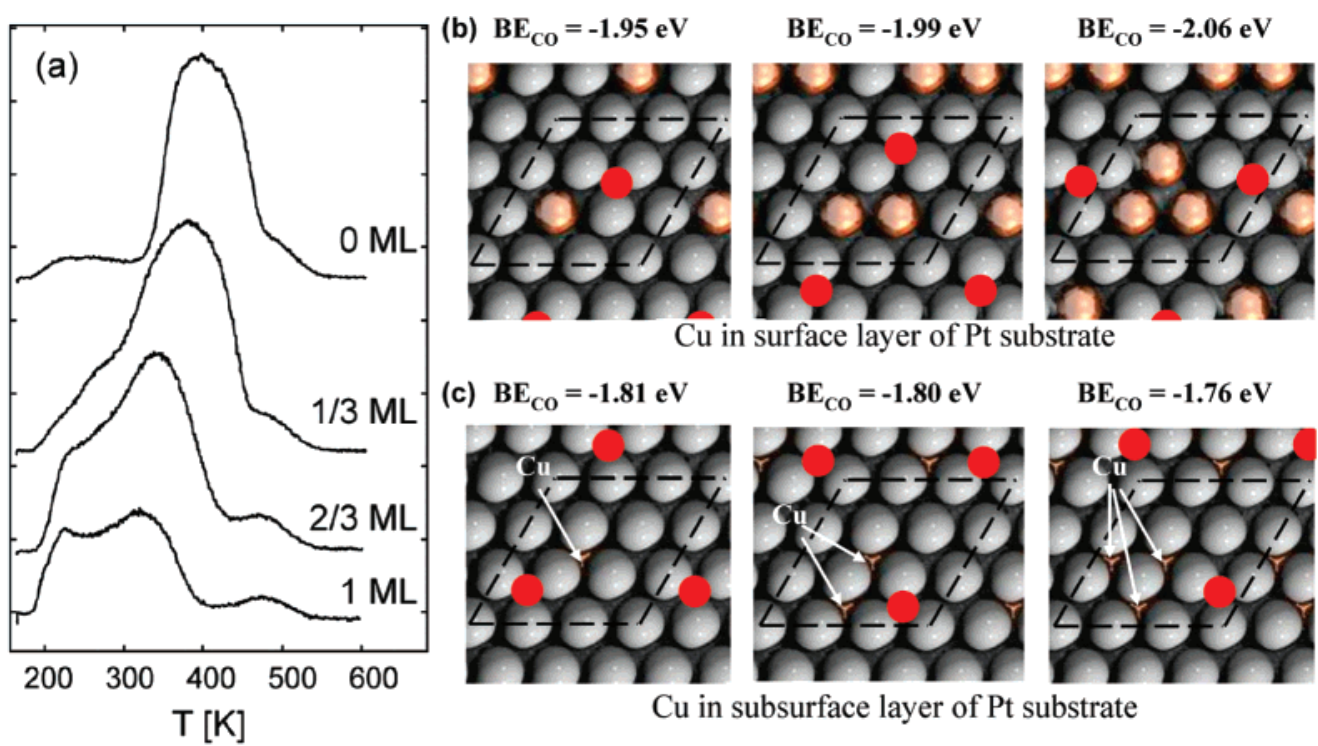

$\mathrm{Cu}$ in surface layer of Pt substrate

\section{(c)}
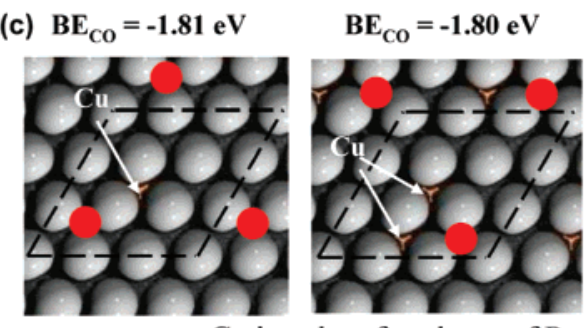

$\mathrm{BE}_{\mathrm{CO}}=-1.76 \mathrm{eV}$

$\mathrm{Cu}$ in subsurface layer of Pt substrate

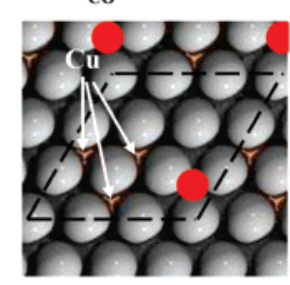

Figure 2. (a) Series of $\mathrm{CO}$ TPD spectra for $\mathrm{Cu} / \mathrm{Pt}(111)$ surface alloys with varying amounts of $\mathrm{Cu}$ after exposure of $10 \mathrm{~L}$ of $\mathrm{CO}$ at $166 \mathrm{~K}$. (b,c) Binding energies for $1 / 9 \mathrm{ML}$ of $\mathrm{CO}$ on different $\mathrm{Cu} / \mathrm{Pt}$ surface and subsurface alloys, respectively, as calculated from a $3 \times 3$ surface unit cell (for comparison, $\mathrm{BE}$ CO on pure $\mathrm{Pt}(111)=-1.82 \mathrm{eV}$ ). Gray and gold spheres represent $\mathrm{Pt}$ and $\mathrm{Cu}$ atoms, respectively. In each of the panels (b) and (c), three top views of the respective alloy slabs are shown: left, 1/9ML of $\mathrm{Cu}$; middle, $2 / 9 \mathrm{ML}$ of $\mathrm{Cu}$; right, 3/9 $\mathrm{ML}$ of $\mathrm{Cu}$. The surface unit cell is sketched in each image, with the most favored $\mathrm{CO}$ adsorption site shown with a red circle. In panel (c), arrows show the location of the subsurface $\mathrm{Cu}$ atoms.

of the interaction between $\mathrm{CO}$ and the $\mathrm{Cu} / \mathrm{Pt} \mathrm{NSA}$; the stronger the interaction, the more likely the site-blocking by $\mathrm{CO}$ would be. In particular, we calculated the binding energy $\left(E_{\mathrm{b}}=E_{\text {total }}\right.$ $\left.-E_{\text {substrate }}-E_{\text {gas-phase adsorbate }}\right)$ of $\mathrm{CO}$ on pure $\mathrm{Pt}(111)$ and on $\mathrm{Cu} / \mathrm{Pt}(111)$ NSAs with varying concentrations of $\mathrm{Cu}$ in the surface and subsurface layers at a CO coverage of 1/9 ML. For reference, the binding energy of $\mathrm{CO}$ on $\mathrm{Pt}(111)$ is found to be $-1.82 \mathrm{eV}$. It should be noted that, although DFT methods are unable to capture the most stable $\mathrm{CO}$ adsorption site on Pt(111), ${ }^{28}$ here we focus only on the trends in $\mathrm{CO}$ binding energies on different surfaces, and these relative trends should not be affected by that inability. When the $\mathrm{Cu}$ coverage for the $\mathrm{Cu}$ overlayer structures was increased from $1 / 9$ to $1 / 3 \mathrm{ML}$, an increase in the magnitude of the binding energy of $\mathrm{CO}$ in the most preferred site (fcc site formed by three Pt atoms) was calculated. The $\mathrm{CO}$ binding energies in these cases amount to $-1.95 \mathrm{eV}$ for $1 / 9 \mathrm{ML}$ of $\mathrm{Cu}$ and $-2.06 \mathrm{eV}$ for $1 / 3 \mathrm{ML}$ of $\mathrm{Cu}$ (see Figure 2b). For the $\mathrm{Cu}$ subsurface alloys of $\mathrm{Pt}(111)$, we observe exactly the opposite behavior. As the $\mathrm{Cu}$ concentration in the second layer of the slab is increased from 1/9 ML to 1/3 $\mathrm{ML}$, the magnitude of the CO binding energy on the most preferred surface site decreases from -1.81 to $-1.76 \mathrm{eV}$, as shown in Figure 2c. As the amount of $\mathrm{Cu}$ in the subsurface layer is further increased to $1 \mathrm{ML}$, the $\mathrm{CO}$ binding is decreased by $0.33 \mathrm{eV}$, to $-1.48 \mathrm{eV}$. CO binding is significantly weaker on a full $\mathrm{ML}$ of $\mathrm{Cu}$ overlayer on top of $\mathrm{Pt}(111)(-1.16 \mathrm{eV})$ as compared to the different structures considered above, but it is important to remember that this structure is not thermodynamically stable because $\mathrm{Cu}$ is clearly more stable in subsurface layers.

The trends in $\mathrm{CO}$ binding energies as predicted by DFT were investigated experimentally by performing TPD measurements on various $\mathrm{Cu} / \mathrm{Pt}(111)$ structures. A series of CO TPD spectra from $\mathrm{Cu} / \mathrm{Pt}(111)$ subsurface alloys, prepared by evaporating

(28) Feibelman, P.; Hammer, B.; Nørskov, J.; Wagner, F.; Scheffler, M.; Stumpf, R.; Watwe, R.; Dumesic, J. J. Phys. Chem. B 2001, 105, 4018-4025. varying amounts of $\mathrm{Cu}$ onto $\mathrm{Pt}(111)$ at $800 \mathrm{~K}$, is depicted in Figure 2a. The TPD spectrum from the pure Pt(111) surface has a broad but distinct peak with a maximum intensity at 400 $\mathrm{K}$ and a small, high-temperature shoulder, which is ascribed to defects such as step edges. ${ }^{29}$ When the amounts of $\mathrm{Cu}$ alloyed into $\mathrm{Pt}(111)$ are increased, the main TPD peak shifts toward lower temperatures, which shows that the $\mathrm{Cu}$ atoms weaken the interaction between the surface alloy and $\mathrm{CO}$. This trend in $\mathrm{CO}$ binding energy as a function of $\mathrm{Cu}$ coverage is exactly what is found in the DFT calculations for the $\mathrm{Cu} / \mathrm{Pt}(111)$ subsurface alloys, but not for the surface alloys. Therefore, the combination of DFT and TPD shows that the thermodynamically stable $\mathrm{Cu}$ / Pt NSA binds CO significantly more weakly than $\mathrm{Pt}(111)$ does, thereby implying a considerable enhancement of CO-tolerance of the $\mathrm{Cu} / \mathrm{Pt}$ NSA surface as compared to that of pure Pt.

Detailed studies of the low-temperature WGS reaction mechanism on a number of late transition metals ${ }^{30}$ suggest that $\mathrm{H}_{2} \mathrm{O}$ activation, and in particular its first step $\left(\mathrm{H}_{2} \mathrm{O} \rightarrow \mathrm{OH}+\right.$ $\mathrm{H}$ ), is the rate-determining step for several of these metals. This includes $\mathrm{Cu}$, the current catalyst of choice for industrial WGS applications, ${ }^{31}$ and Pt. Accordingly, we have studied the minimum energy path of water activation on three different model surfaces, $\mathrm{Cu}(111), \mathrm{Pt}(111)$, and a full $\mathrm{ML}$ of $\mathrm{Cu}$ in the first subsurface layer of a $\mathrm{Pt}(111)$ slab. As shown above, $\mathrm{Cu}$ preferentially segregates into the first subsurface layer of $\mathrm{Pt}(111)$ without necessarily reaching a full ML coverage in that layer. However, previous calculations on $\mathrm{NSAs}^{8}$ showed that positive kinetic effects (such as decreased activation energies) observed at full ML subsurface alloys tend to be preserved by-and-large, even in the case of less than a ML of solute coverage in the subsurface layer. This finding reflects the importance of local

(29) Pedersen, M. O.; Helveg, S.; Ruban, A.; Stensgaard, I.; Laegsgaard, E.; Norskov, J. K.; Besenbacher, F. Surf. Sci. 1999, 426, 395-409.

(30) Gokhale, A. A. Ph.D. thesis, University of Wisconsin-Madison, 2005.

(31) Chorkendorff, I.; Niemantsverdriet, J. W. Concepts of Modern Catalysis and Kinetics; Wiley-VCH: Weinheim, 2003. 

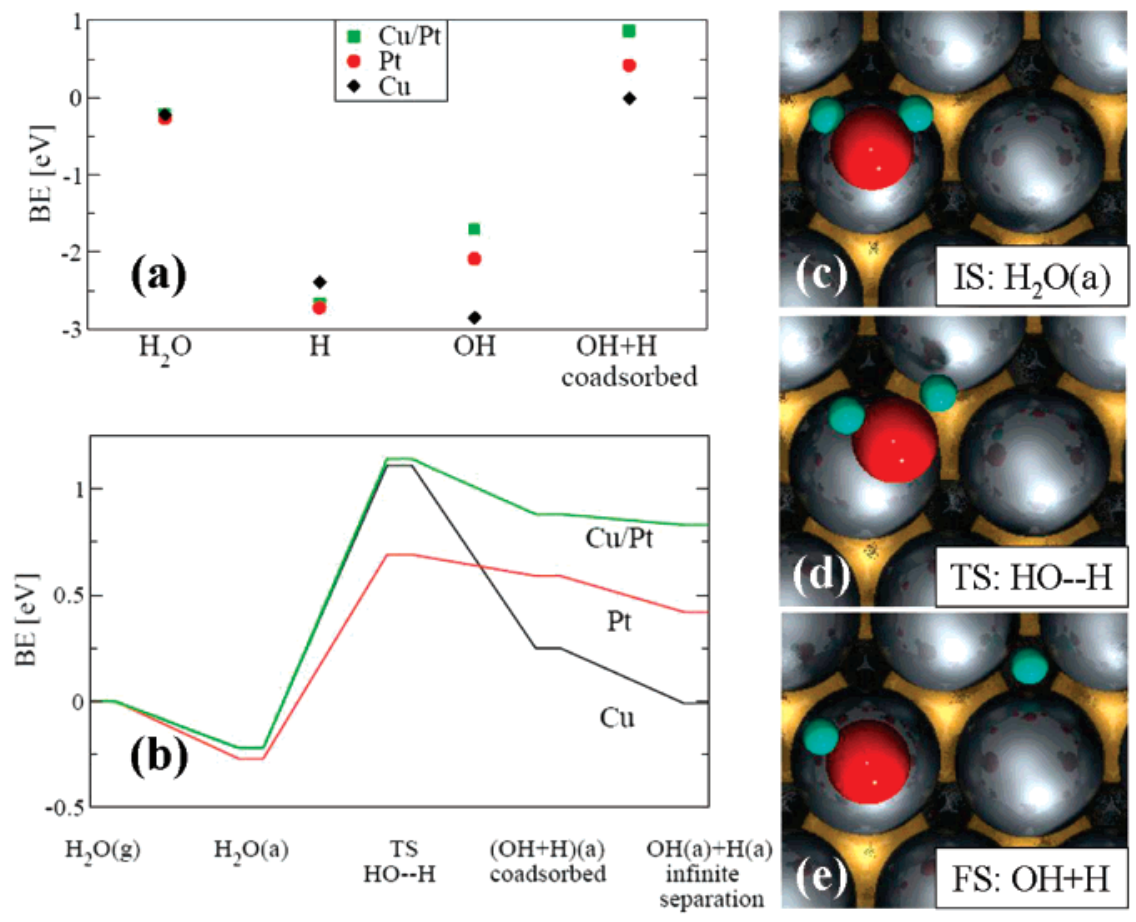

Figure 3. (a) Binding energies (BE) of $\mathrm{H}_{2} \mathrm{O}\left(\mathrm{ref} \mathrm{H}_{2} \mathrm{O}(\mathrm{g})\right.$ ), $\mathrm{H}\left(\right.$ ref $\mathrm{H}(\mathrm{g})$ ), $\mathrm{OH}$ (ref $\mathrm{OH}(\mathrm{g})$ ), and coadsorbed $\mathrm{OH}+\mathrm{H}\left(\mathrm{ref} \mathrm{H}_{2} \mathrm{O}(\mathrm{g})\right)$ on $\mathrm{Cu}(111)$, $\mathrm{Pt}(111)$, and $\mathrm{Cu} / \mathrm{Pt}(111)$, all calculated on a $2 \times 2$ unit cell, for the energetically preferred states. (b) Potential energy diagram for the activation of $\mathrm{H}_{2} \mathrm{O}$ on $\mathrm{Cu} / \mathrm{Pt}(111)$ subsurface alloy, $\mathrm{Cu}(111)$, and $\mathrm{Pt}(111)$ with $\mathrm{H}_{2} \mathrm{O}(\mathrm{g})$ as the zero of the energy axis. (c-e) Top view of DFT-calculated structures for the initial (IS), transition (TS), and final (FS) states of $\mathrm{H}_{2} \mathrm{O}$ activation on the $\mathrm{Cu} / \mathrm{Pt}(111)$ subsurface alloy. Red, green, gray, and gold spheres represent $\mathrm{O}, \mathrm{H}, \mathrm{Pt}$, and $\mathrm{Cu}$ atoms, respectively.

electronic structure in determining specific site reactivity. Thus, by choosing a high-symmetry, full ML Cu/Pt subsurface alloy, we can examine the influence of subsurface $\mathrm{Cu}$ on the reactivity of the Pt surface.

The binding energies at their preferred adsorption sites of $\mathrm{H}$, $\mathrm{OH}$, and $\mathrm{H}_{2} \mathrm{O}$ on all three surfaces are shown in Figure 3a. We find that, in the $2 \times 2$ unit cell, $\mathrm{H}$ and $\mathrm{OH}$ occupy three-fold fcc sites on all three surfaces, with the exception of $\mathrm{OH}$ occupying top/bridge site on the pure $\mathrm{Pt}(111)$ surface. In the relevant coadsorbed states, representing the final state of $\mathrm{H}_{2} \mathrm{O}$ activation, $\mathrm{OH}$ and $\mathrm{H}$ occupy top $-\mathrm{fcc}, \mathrm{fcc}-\mathrm{fcc}$, and top-top combinations of sites on $\mathrm{Cu} / \mathrm{Pt}(111), \mathrm{Cu}(111)$, and $\mathrm{Pt}(111)$, respectively. The variation in the binding energy of $\mathrm{H}$ on these three surfaces is small (within $0.20 \mathrm{eV}$ ) as compared to the corresponding variation of the $\mathrm{OH}$ binding energy $(1.15 \mathrm{eV})$. $\mathrm{OH}$ binds to $\mathrm{Cu} / \mathrm{Pt}(111)$ with $-1.70 \mathrm{eV}$, significantly weaker than on $\mathrm{Cu}(111)$ and $\mathrm{Pt}(111)$, to which it binds with -2.85 and $-2.09 \mathrm{eV}$, respectively. $\mathrm{H}_{2} \mathrm{O}$ interacts rather weakly with all three surfaces.

Following the trend in relative stability of adsorbed $\mathrm{OH}$ discussed above, the coadsorbed state of the products for the $\mathrm{H}_{2} \mathrm{O} \rightarrow \mathrm{OH}+\mathrm{H}$ step is most stable on $\mathrm{Cu}(111)$, followed by $\mathrm{Pt}(111)$ and then by $\mathrm{Cu} / \mathrm{Pt}(111)$. A significant repulsion between coadsorbed $\mathrm{OH}$ and $\mathrm{H}$ calculated on the $\mathrm{Cu}(111)$ surface tends to stabilize the products of this reaction even further when $\mathrm{OH}$ and $\mathrm{H}$ can diffuse away from each other (compare the coadsorbed state and infinite separation state, as shown in Figure $3 b)$. However, this is not the case on the other two surfaces, where the repulsive interaction between coadsorbed $\mathrm{OH}$ and $\mathrm{H}$ is only minimal. Figure $3 \mathrm{~b}$ shows that the activation energy barrier for the $\mathrm{H}_{2} \mathrm{O} \rightarrow \mathrm{OH}+\mathrm{H}$ elementary step is the smallest on $\mathrm{Pt}(111)$, a modest $0.96 \mathrm{eV}$, whereas the corresponding barriers on $\mathrm{Cu}(111)$ and $\mathrm{Cu} / \mathrm{Pt}(111)$ subsurface alloy are 1.34 and $1.36 \mathrm{eV}$, respectively. Top views of the initial, transition, and final states for this elementary step on the $\mathrm{Cu} / \mathrm{Pt}$ surface are shown in Figure $3 \mathrm{c}-$ e. We note in passing that, although $\mathrm{Cu}$ (111) binds $\mathrm{OH}(\mathrm{a})+\mathrm{H}(\mathrm{a})$ more strongly than $\mathrm{Pt}(111)$ does, the latter appears to break the $\mathrm{H}-\mathrm{OH}$ bond more easily than the former. The $\mathrm{H}-\mathrm{OH}$ bond-breaking steps on $\mathrm{Cu}(111)$ and on the subsurface alloy $\mathrm{Cu} / \mathrm{Pt}(111)$ have similar transition state (TS) energies. However, the NSA offers a considerable advantage, namely that the product of the reaction, $\mathrm{OH}$, is bound much more weakly than $\mathrm{OH}$ on $\mathrm{Cu}(111)$, and therefore the potential for catalyst poisoning by that intermediate is reduced on the $\mathrm{Cu} / \mathrm{Pt}$ alloy. The activation energy barrier for $\mathrm{H}_{2} \mathrm{O}$ activation on $\mathrm{Pt}(111)$ is the smallest of those on all three surfaces studied (see Figure 3). Nevertheless, CO poisoning of pure Pt catalysts is the main reason for the low WGS activity observed on those catalysts.

Formate intermediate (HCOO) is another key WGS reaction intermediate known to be rather stable on $\mathrm{Cu}$ surfaces. ${ }^{30} \mathrm{In}$ particular, formate species occupy a large fraction of $\mathrm{Cu}$ surface sites under typical WGS conditions, thereby blocking them from participating in active WGS chemistry. Our calculations show that, following the relative binding energy trends established for $\mathrm{OH}$ between $\mathrm{Cu}$ and $\mathrm{Cu} / \mathrm{Pt} \mathrm{NSA}$, formate is also destabilized on the $\mathrm{Cu} / \mathrm{Pt}(111) \mathrm{NSA}$ by ca. $0.9 \mathrm{eV}$ at $1 / 9 \mathrm{ML}$ coverage, compared to its binding on pure $\mathrm{Cu}(111)$. This finding suggests that $\mathrm{Cu} / \mathrm{Pt}$ NSA catalysts should be able to activate $\mathrm{H}_{2} \mathrm{O}$ as easily as $\mathrm{Cu}$ and, at the same time, be less prone to $\mathrm{CO}$ poisoning than pure Pt and more resistant to site blocking by formate than pure $\mathrm{Cu}$ surfaces would be.

On the basis of our first-principles calculations, we therefore predict that the reduced poisoning by $\mathrm{CO}$ and formate on the $\mathrm{Cu} / \mathrm{Pt}$ subsurface alloy should make this NSA a very promising and active WGS catalyst. We note here that, as for $\mathrm{H}_{2}$ dissociation, an NSA is indeed able to activate the $\mathrm{H}-\mathrm{OH}$ bond 
in $\mathrm{H}_{2} \mathrm{O}$ relatively easily while binding the products of the reaction rather weakly. ${ }^{8}$ Furthermore, the NSAs of $\mathrm{Cu} / \mathrm{Pt}$ are found to be stable in $\mathrm{CO}$-rich environments, and $\mathrm{CO}$-induced segregation is therefore not expected. ${ }^{13}$

We have thus shown that the stable $\mathrm{Cu} / \mathrm{Pt}$ NSA is able to activate $\mathrm{H}_{2} \mathrm{O}$ (a very common reactant) easily and, at the same time, to bind the products of that reaction and formate intermediates rather weakly, thus avoiding possible poisoning of the catalyst surface. Interestingly, we would like to mention that recently Zhou et al. ${ }^{32}$ reported an anomalously high catalytic activity of CuPt core-shell nanoparticles for the NO reduction reaction. After a thorough characterization of their nanoparticles, those authors concluded that the most active phase of their catalysts had $\mathrm{Cu}$ preferentially located in the subsurface layers of the Pt nanoparticles.

\section{Conclusions}

By using a combination of experimental and theoretical model studies, we identified a novel $\mathrm{Cu} / \mathrm{Pt}$ near-surface alloy which was shown to be a promising candidate for an improved lowtemperature WGS catalyst. Such an NSA catalyst might be extremely relevant to hydrogen economy-related catalysis and

(32) Zhou, S. H.; Varughese, B.; Eichhorn, B.; Jackson, G.; McIlwrath, K. Angew. Chem., Int. Ed. 2005, 44, 4539-4543. practice. Advanced nanosynthesis techniques, including electrochemical deposition of metals on metals, ${ }^{33}$ dendrimer-based approaches, ${ }^{34}$ and atomic layer deposition ${ }^{35}$ techniques, all hold a very strong promise for large-scale preparation of NSA catalysts with superior performance when compared to monometallic or bulk alloy catalysts. Such emerging catalyst nanosynthesis techniques can enable the large-scale preparation of improved catalysts, and we hope that the present study will inspire such advances.

Acknowledgment. The authors thank Zheshen Li for his help with the XPS experiments. Work at the University of Wisconsin was supported partly by DOE-BES, Chemical Sciences Division, and partly by grant DE-FG26-06NT42740. We also thank S. C. Johnson \& Son, Inc. for a fellowship to A.U.N. Supercomputing time at NERSC, PNNL, and ORNL resources is gratefully acknowledged. J.S. acknowledges financial support by the European Commission through a Marie-Curie IntraEuropean Fellowship.

JA0700855

(33) Brankovic, S. R.; Wang, J. X.; Adzic, R. R. Surf. Sci. 2001, 474, L173L179.

(34) Ye, H. C.; Crooks, R. M. J. Am. Chem. Soc. 2005, 127, 4930-4934.

(35) Lim, B. S.; Rahtu, A.; Gordon, R. G. Nat. Mater. 2003, 2, 749-754. 